Article

\title{
Experimental Investigation of Porous and Mechanical Characteristics of Single-Crack Rock-like Material under Freeze-Thaw Weathering
}

\author{
Songtao Yu ${ }^{1,2,3}$, Yuxian Ke ${ }^{1,4, *}$, Hongwei Deng ${ }^{5}$, Guanglin Tian ${ }^{5}$ and Junren Deng ${ }^{5}$ \\ 1 Jiangxi Province Key Laboratory of Mining Engineering, Jiangxi University of Science and Technology, \\ Ganzhou 341000, China; yusongtao92@163.com \\ 2 School of Emergency Management, Jiangxi University of Science and Technology, Ganzhou 341000, China \\ 3 Center for Emergency Management and Multidisciplinary Innovation Research, Jiangxi University of Science \\ and Technology, Ganzhou 341000, China \\ 4 School of Resource and Environmental Engineering, Jiangxi University of Science and Technology, \\ Ganzhou 341000, China \\ 5 School of Resource and Safety Engineering, Central South University, Changsha 410083, China; \\ denghw208@163.com (H.D.); 185512098@csu.edu.cn (G.T.); csudjr@163.com (J.D.) \\ * Correspondence: keyuxian@jxust.edu.cn; Tel.: +86-135-766-858-66
}

Citation: Yu, S.; Ke, Y.; Deng, H.; Tian, G.; Deng, J. Experimental Investigation of Porous and Mechanical Characteristics of Single-Crack Rock-like Material under Freeze-Thaw Weathering. Minerals 2021, 11, 1318. https:// doi.org $/ 10.3390 / \min 11121318$

Academic Editor: Gianvito Scaring

Received: 27 October 2021

Accepted: 24 November 2021

Published: 26 November 2021

Publisher's Note: MDPI stays neutral with regard to jurisdictional claims in published maps and institutional affiliations.

Copyright: (c) 2021 by the authors. Licensee MDPI, Basel, Switzerland. This article is an open access article distributed under the terms and conditions of the Creative Commons Attribution (CC BY) license (https:/ / creativecommons.org/licenses/by/ $4.0 /)$.

\begin{abstract}
Freeze-thaw weathering changes the pore structure, permeability, and groundwater transportation of rock material. Meanwhile, the change in rock material structure deduced by frost heaving deteriorates mechanical properties of rock material, leading to instability and insecurity of mine slopes in cold regions. In this paper, rock-like specimens containing prefabricated cracks at different angles and having undergone various freeze-thaw cycles are used as the object. Their pore structure, compressive mechanical properties, strain energies, failure characteristics, and the connection between pore structure and mechanical properties are analyzed. Results show that the porosity, spectrum area of mesopores, and spectrum area of macropores increase with the increase in freeze-thaw cycles, while crack angle shows no obvious influence on pore structure. Peak stress and elastic modulus drop with the increase in freeze-thaw cycles, while peak strain shows an increasing trend. Peak stress and elastic modulus decrease in the beginning, and then increase with the increase in crack angle, while peak strain shows a reverse trend. Elastic strain energy and pre-peak strain energy drop with the increase in freeze-thaw cycles. Elastic strain energy decreases first, and then increases with the increase in crack angle. The correlation between the spectrum area of macropores and elastic modulus is the strongest among different pores. Elastic modulus and peak stress decrease with the increase in macropore spectrum area, and peak strain increases with the increase in macropore spectrum area.
\end{abstract}

Keywords: freeze-thaw; pore structure; groundwater seepage; mechanical properties; strain energy

\section{Introduction}

Under freeze-thaw (F-T) weathering, the pore structure characteristics, seepage characteristics, mechanical characteristics, groundwater contamination and stability of rock material change greatly [1-4]. On the one hand, frost heave induced by water-ice phase transition casts tensile stress on cracks, leading to the initiation and extension of pores and cracks; additionally, water-rock reaction deteriorates connections between rock aggregate [5-7]. On the other hand, cracks provide interspaces for F-T weathering.

Therefore, the pore structure, groundwater transportation, and groundwater contamination of mines in cold regions that have undergone F-T cycles are different from those in regular areas. Additionally, changes in pore structure cause the deterioration of the mechanical characteristics of rock material, which induces instability and insecurity of mine slope engineering [8-10]. From this point of view, conducting an investigation 
on porous and mechanical characteristics of rock material under F-T weathering is of great importance to groundwater contamination control, slope stability maintenance, etc. Meanwhile, cracks control the mechanical properties and failure of rock material. Thus, investigating the porous and mechanical characteristics of single-crack rock material under freeze-thaw weathering is also significant for the reliability and stability of mining and civil engineering projects.

Pore structure and mechanical properties of rock material under F-T weathering have attracted the attention of many scholars [11-14]. Using rock-like samples with prefabricated cracks as the research object, Lu et al. investigated the effects of F-T cycles, crack geometric parameters, and confining pressures on compressive mechanical properties [15] and summarized the deterioration mode of fractured samples. By taking crack geometric parameters, crack filling types, filling thickness, sample saturation, and F-T cycles as variables, Liu et al. studied their influences on the failure mode, uniaxial strength, and elastic modulus [16]. In order to provide some reference for the stability evaluation of rock engineering in cold regions, Si et al. studied the influence of freeze-thaw-deduced damage on the crack growth process of rock material [17]. Jia et al. studied deformation characteristics of granite with a single crack under three freezing modes and analyzed the crack propagation mechanism [18]. Zhai et al. also investigated the deterioration and fragmentation of rock structures in cold regions that experienced F-T cycles $[19,20]$.

In terms of microstructure detection and damage characterization, many attempts have been made by researchers [21-23]. Mousavi and Javier adopted scanning electron microscopy (SEM) to observe the damage process of rock during cyclic F-T weathering, and they revealed the process of crack propagation [24,25]. Ruiz and Raynaud used computerized tomography (CT) scanning technology to detect the internal pore structure of rock and then studied the effect of F-T weathering on pore structure evolution $[26,27]$. Kucharczyková et al. combined an acoustic emission system and fracture tests to measure the damage caused by F-T weathering of concrete [28]. Li et al. adopted nuclear magnetic resonance (NMR) to detect rock pore structure treated by an acidic solution, alkaline solution, saline solution, and F-T cycles $[29,30]$. Deng et al. used NMR to reveal the pore structure evolution of sandstone under coupled effects of acid erosion and F-T weathering [31,32]. Liu et al. applied NMR to obtain porosity and transverse relaxation time $\left(\mathrm{T}_{2}\right)$ of F-T treated rock, and then established the connection between porosity and mechanical parameters $[33,34]$. Jia et al. revealed the pore structure evolution of sandstone under F-T cycles through porosity, pore size distribution, permeability, and tortuosity gained by NMR [35]. Qin et al. investigated petrophysical properties of coal subjected to liquid nitrogen F-T treatment through NMR [36].

As energy is the inner driver of material deformation and failure and it also characterizes damage of material to some extent, researchers focus on the energy evolution of rock under F-T weathering [37-39]. Yu et al. analyzed total input strain energy, releasable elastic strain energy, and dissipated energy of F-T-treated sandstone under uniaxial compression [40]. By conducting dynamic tests on F-T-treated sandstone, Zhang et al. revealed the variation laws of pre-peak strain energy, peak strain energy, post-peak strain energy, total strain energy, and elastic strain energy of F-T cycles [41]. Liu et al. investigated the evolution of incident energy, reflected energy, and dissipation energy of granite, considering both F-T cycles and dynamic loading rates [42].

The above studies generally focused on pore structure, mechanical properties, and the connection between mechanical properties and porosity of rock under F-T weathering. However, research on the connection between mechanical properties, various sizes of pores, and strain energy evolution of F-T-treated rock material is not yet sufficient. In this study, rock-like specimens containing a single crack at different angles are subjected to F-T weathering. They are then adopted to conduct NMR tests and uniaxial compression tests to obtain pore size distribution and static mechanical properties. The evolution trends of porosity, micropore spectrum area, mesopore spectrum area, macropore spectrum area, peak stress, peak strain, and elastic modulus of F-T cycles and crack angles are analyzed. 
Then, the characteristics of dissipation energy, elastic strain energy, and pre-peak strain energy of specimens under various F-T cycles and crack angles are studied. Additionally, the connection between pore sizes and mechanical properties is also investigated. Finally, failure characteristics of specimens under different F-T cycles and crack angles are analyzed.

\section{Materials and Methods}

\subsection{Specimen Preparation}

\subsubsection{Materials}

Specimens used in this paper were rock-like specimens containing a single crack, the prototype of which was sandstone from an open-pit mine located in Shandong province, northern China. It was based on two considerations that it was decided to replace sandstone with rock-like material. One is that cracks with different angles are easier to manufacture in rock-like material without disturbing specimens. The other reason is that rock-like material is much cheaper than sandstone under the premise that their physical and mechanical properties are very close. Specimens were made of river sand, P.O 42.5 Portland cement, silicon powder, naphthalene water reducer, and pure water. The main components and their properties are shown in Tables 1-3.

Table 1. The main components of P.O 42.5 Portland cement.

\begin{tabular}{|c|c|c|c|c|}
\hline Components & $3 \mathrm{Ca} . \mathrm{SiO}_{2}$ & $2 \mathrm{Ca} . \mathrm{SiO}_{2}$ & 3Cao. $\mathrm{Al}_{2} \mathrm{O}_{3}$ & $4 \mathrm{Cao} . \mathrm{Al}_{2} \mathrm{O}_{3} \cdot \mathrm{MgO}$ \\
\hline Content & $52.8 \%$ & $20.7 \%$ & $11.5 \%$ & $8.8 \%$ \\
\hline
\end{tabular}

Table 2. Main parameters of other materials.

\begin{tabular}{ccccc}
\hline Material Type & Appearance & Main Ingredient & Particle Size & Density \\
\hline River sand & Light yellow particle & $98.5 \%$ Quatz, 1.5\% Mud & $0.5-1.0 \mathrm{~mm}$ & $1.83 \mathrm{~g} / \mathrm{cm}^{3}$ \\
Silicon powder & White powder & $99.9 \% \mathrm{SiO}_{2}$ & $1 \mu \mathrm{m}$ & $2.4 \mathrm{~g} / \mathrm{cm}^{3}$ \\
$\begin{array}{c}\text { Naphthalene water } \\
\text { reducer }\end{array}$ & Yellow powder & $\begin{array}{c}\beta-\text { Naphthal-enesulfonate } \\
\text { sodium formaldehyde } \\
\text { condensate }\end{array}$ & \\
\hline
\end{tabular}

Table 3. Initial parameters of specimens and prototype sandstone.

\begin{tabular}{cccccc}
\hline Material & Density $\left(\mathbf{g} / \mathbf{c m}^{\mathbf{3}}\right)$ & UCS $\mathbf{( M P a )}$ & UTS (MPa) & P Wave Speed (m/s) & Porosity $(\mathbf{\%})$ \\
\hline $\begin{array}{c}\text { Rock-like material } \\
\begin{array}{c}\text { Prototype } \\
\text { sandstone }\end{array}\end{array}$ & 2.23 & 32.01 & 3.26 & 4078.35 & 3.186 \\
\hline
\end{tabular}

\subsubsection{Specimen Production}

Specimens adopted in this paper were rock-like material made with cement, water, sand, silicon powder, and naphthalene water reducer with a mass ratio of 1.00:0.32:1.30:0.10:0.01. Specimens were made into a cylinder with a diameter of $50 \mathrm{~mm}$ and a height of $100 \mathrm{~mm}$ according to Rock Test Rules for Water Conservancy and Hydropower Projects (SL/T 264-2020) [43]. Perforated cracks were prefabricated by a steel bar with a thickness of $1 \mathrm{~mm}$ and a width of $15 \mathrm{~mm}$. There were 6 groups of specimens in this study, corresponding to specimens that underwent 0, 20, 40, 60, 80, and 100 F-T cycles, respectively. Each group contained 5 sets of specimens, corresponding to crack angles of $0^{\circ}, 30^{\circ}, 45^{\circ}, 60^{\circ}$, and $90^{\circ}$. Each set included 3 specimens, and 90 specimens were included in total.

Procedures of specimen production are as follows.

1. Material weighting. Cement, water, sand, silicon powder, and naphthalene water reducer were weighted according to the above mass ratio.

2. Material filling. Materials were mixed sufficiently, and then models were prepared. The steel bar was set in the middle of the plastic model for crack making. To prevent 
materials from sticking to the model and steel bar, the steel bar and inner wall of the model were coated with oil. After that, mixed materials were filled into fabricated plastic models.

3. Vibrating. Models filled with materials were put on the vibrating device. Then, the specimens were vibrated until bubbles longer occurred.

4. Demolding and curing. After $24 \mathrm{~h}$ of specimen vibration, solid specimens were demolded. Then, specimens were numbered and placed into a standard curing box. The curing temperature, humidity, and curing time were set to $22{ }^{\circ} \mathrm{C}, 98 \%$, and 28 days, respectively. Schematic diagrams of specimens are shown in Figure 1.
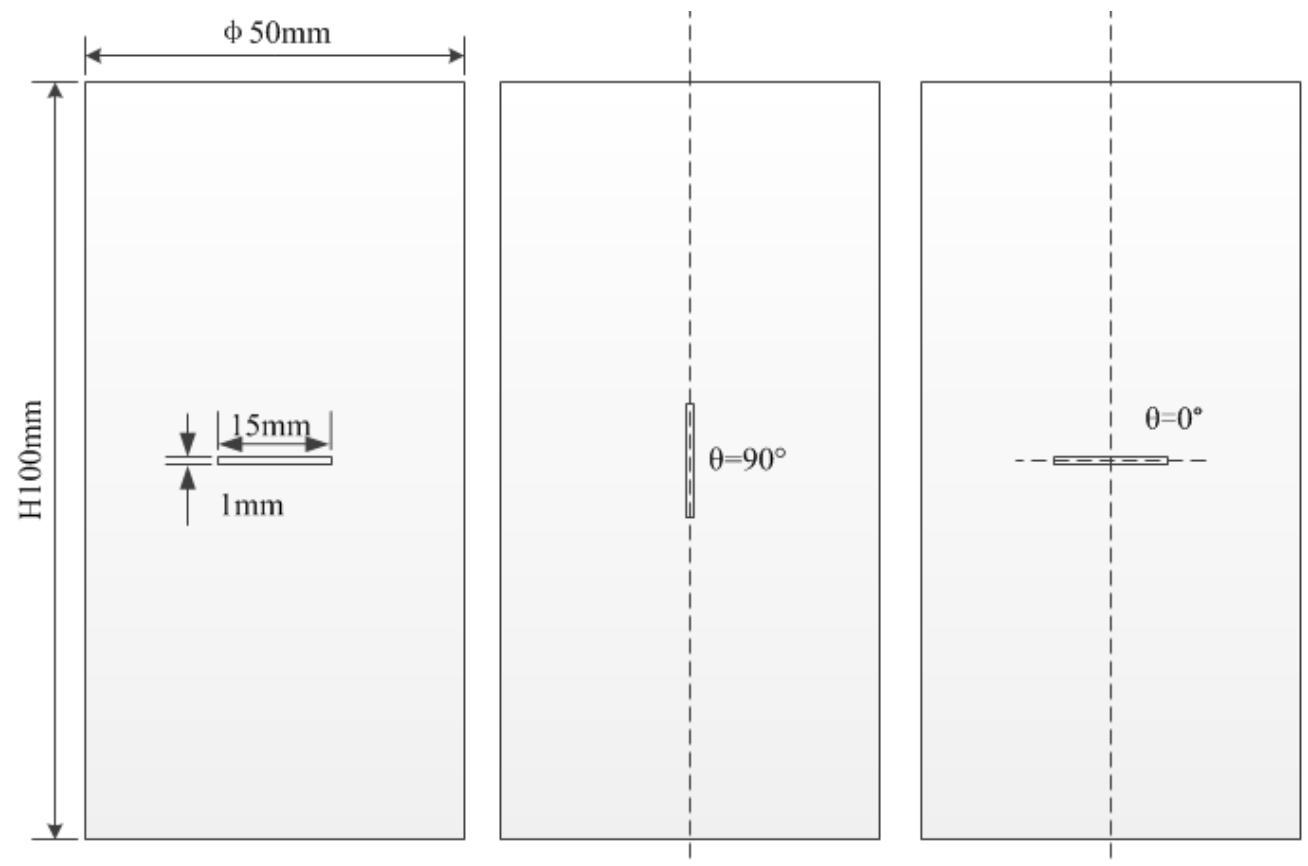

Figure 1. Schematic diagrams of specimen.

\subsection{Pivotal Facilities}

\subsubsection{Freeze-Thaw Test Machine}

The freeze-thaw test machine adopted in this study was the TDS-300 type freezethaw test machine, manufactured by Donghua experimental instrument Co., Ltd., Suzhou, China $[44,45]$. Parameters including freezing temperature, thawing temperature, freezing time, and thawing time were automatically controlled by this device after they were set up in advance. The device-controlled temperature had a precision of $0.1^{\circ} \mathrm{C}$ in the range of $-40^{\circ} \mathrm{C}$ to $+20^{\circ} \mathrm{C}$. Maximum F-T cycles reached a value of 999 . Figures of the freeze-thaw test machine are included in Figure 2. 


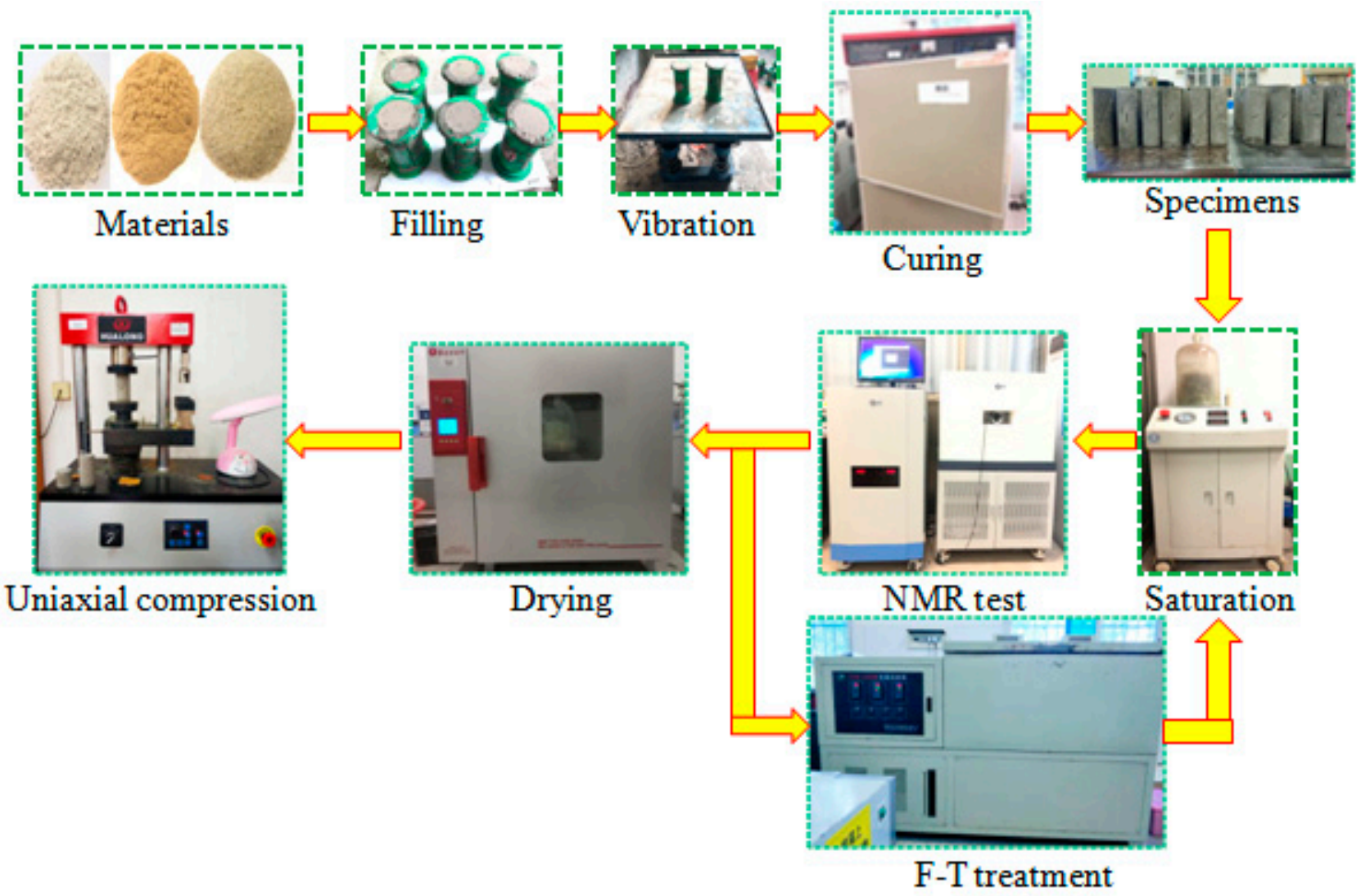

Figure 2. Schematic diagram of experimental procedures.

\subsubsection{NMR System}

The NMR system applied in this study contained an NMR test device and a saturation device [46]. The NMR test device in this study was a MiniMR-60 type low-field nuclear magnetic resonance analysis system. The magnetic field generated by the system was around $0.3 \pm 0.05 \mathrm{~T}$. The resonance frequency of this NMR device sensitive for $\mathrm{H}^{+}$ was $21.7 \mathrm{MHz}$. The MiniMR-60 system provided a radio frequency ranging from 1.0 to 49.9 MHz within the magnetic field. The vacuum saturation device was an affiliated device of the NMR system. It was used to completely saturate specimens to characterize pore structure when conducting NMR tests. The vacuum saturation device generated $-0.1 \mathrm{MPa}$ vacuum pressure when it worked, and the maximum vacuum time reached $12 \mathrm{~h}$. Figures of the NMR system are included in Figure 2.

\subsubsection{Uniaxial Compression Device}

A WHY-300 microcomputer-controlled compression test machine was adopted in this study for uniaxial compression. The device was manufactured by Shanghai Hualong Testing Instrument Co., Ltd., Shanghai, China. It was computer-controlled, and it provided both displacement-control mode and force-control mode when loading. The max loading force was $300 \mathrm{KN}$, the precision of loading force was $0.001 \mathrm{~N}$, and the precision of displacement was $0.001 \mathrm{~mm}$. The figure of the compression device is also included in Figure 2.

\subsubsection{Other Facilities}

Except for these devices mentioned above, a vibration table, a standard curing box, and a drying oven were also used. The amplitude of the vibration table was within the range of $0.3 \mathrm{~mm}$ to $0.6 \mathrm{~mm}$, and the vibration frequency was 2860 times $/ \mathrm{min}$. The temperature-control precision of the curing box was $0.1^{\circ} \mathrm{C}$, the humidity-control range was $95 \%$ to $100 \%$, and the humidity-control precision was $1 \%$. The temperature range of 
the drying oven was $5{ }^{\circ} \mathrm{C}$ to $250{ }^{\circ} \mathrm{C}$, the temperature precision was $0.1^{\circ} \mathrm{C}$, and the max drying time reached $100 \mathrm{~h}$. Figures of these facilities are included in Figure 2.

\subsection{Experiment Design}

\subsubsection{Freeze-Thaw Test}

Specimens used for freeze-thaw weathering need to be saturated in advance. In this study, specimens were saturated in the vacuum saturation device, the vacuum pressure was set as $-0.1 \mathrm{MPa}$, and the vacuum time was set as $12 \mathrm{~h}$. After that, specimens were immersed in water for $24 \mathrm{~h}$ to make sure they were fully saturated. During the F-T test, the freezing temperature was set as $-20^{\circ} \mathrm{C}$, the thawing temperature was set as $+20^{\circ} \mathrm{C}$, and both of the freezing time and the thawing time were set as $4 \mathrm{~h}[32,40]$. F-T cycles were set as $0,20,40,60,80$, and 100 in this study. When the set F-T cycles were reached, specimens were taken out, immersed in water, and ready for the NMR test.

\subsubsection{NMR Test}

Before the NMR test, specimens need to be saturated, as in Section 2.3.1. After saturation, specimens were wiped with a towel and wrapped with plastic films to reduce test error. NMR tests were then conducted on the MiniMR-60 system. During the test, magnet temperature was kept at $32{ }^{\circ} \mathrm{C}$, the center frequency was $12 \mathrm{MHz}$, the sampling number was 4 , the receiver bandwidth was $200 \mathrm{KHz}$, the interval between repeated sampling was $6000 \mathrm{~ms}$, and the number of echoes was 7000. After the NMR test, the porosity and $T_{2}$ spectrum of specimens were obtained.

\subsubsection{Uniaxial Compression Test}

The uniaxial compression test was conducted on a WHY-300 device, a microcomputercontrolled compression test machine. It was used for testing mechanical properties of F-T weathering-treated specimens after the NMR test. Specimens were dried at $60^{\circ} \mathrm{C}$ for $24 \mathrm{~h}$ in advance to avoid the effects of thermal fracture and water content on mechanical properties $[47,48]$. In the test, displacement control was selected as loading mode, and the displacement loading rate was set as $0.1 \mathrm{~mm} / \mathrm{min}$. Through the uniaxial compression test, stress-strain curve, peak stress, peak strain, and elastic modulus were obtained.

The schematic diagram of experimental procedures is also shown in Figure 2.

\section{Results}

\subsection{Pore Structure}

Pore structure influenced by F-T cycles and crack angles is analyzed in this section. Figure 3 a displays the porosity variation of specimens containing $0^{\circ}$ angle cracks under various F-T cycles. It shows that porosity increases linearly with increasing F-T cycles. More specifically, the average initial porosity of specimens is $3.186 \%$, and it reaches $3.356 \%$, $3.913 \%, 4.461 \%, 5.449 \%$, and $6.408 \%$, respectively, after 20, 40, 60, 80, and $100 \mathrm{~F}-\mathrm{T}$ cycles. Namely, it gains a porosity growth rate of $5.336 \%, 22.819 \%, 45.669 \%, 71.030 \%$, and $101.13 \%$, respectively.

In terms of the influence of crack angles on porosity, no obvious variation trend was observed. As seen in Figure 3b, the porosity of specimens after 100 F-T cycles fluctuates with the increase in crack angles. Figure $3 \mathrm{~b}$ shows that average porosities of specimens are $6.408 \%, 7.238 \%, 6.042 \%, 5.640 \%$, and $6.840 \%$, respectively, when crack angles are $0^{\circ}, 30^{\circ}$, $45^{\circ}, 60^{\circ}$, and $90^{\circ}$. This reveals that crack angles have no obvious influence on the porosity of F-T-treated specimens.

To further analyze the pore structure evolution of specimens, the influence of F-T cycles and crack angles on pore size distribution is also analyzed. In this paper, pores are divided into three types, namely micropore $(\mathrm{r}<0.1 \mu \mathrm{m})$, mesopore $(0.1-1 \mu \mathrm{m})$ and macropore $(r \geq 1 \mu \mathrm{m})[49,50]$. Spectrum areas of different pore size ranges are adopted to represent volumes of pores among different pore size ranges. Additionally, as shown in Figure $3 \mathrm{~b}$ and analyzed above, crack angles have no obvious influence on the porosity 
of F-T-treated specimens; therefore, the influence of crack angles on pore structure is no longer analyzed in the following content.

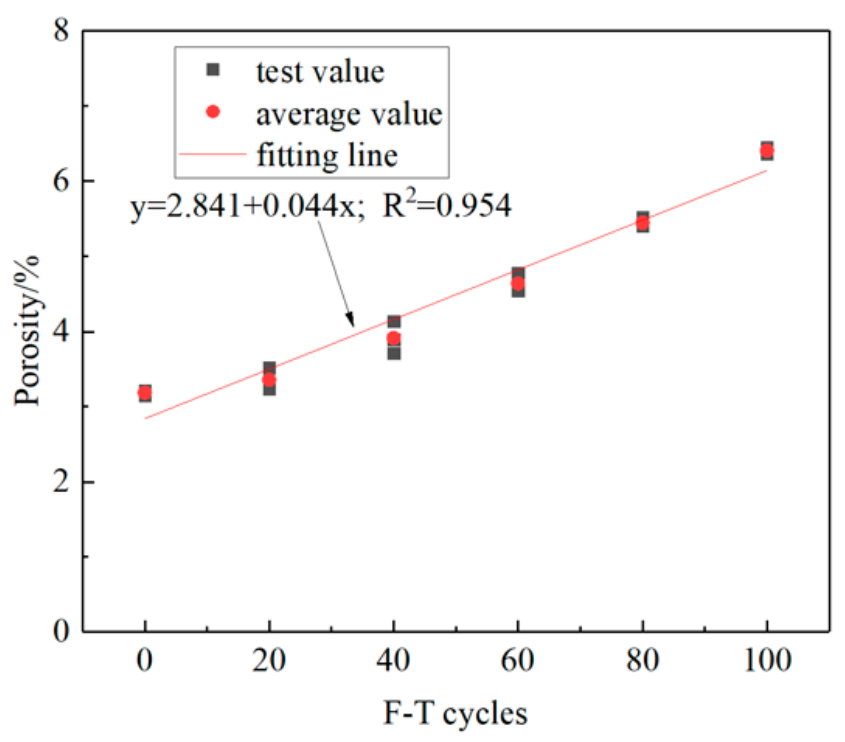

(a)

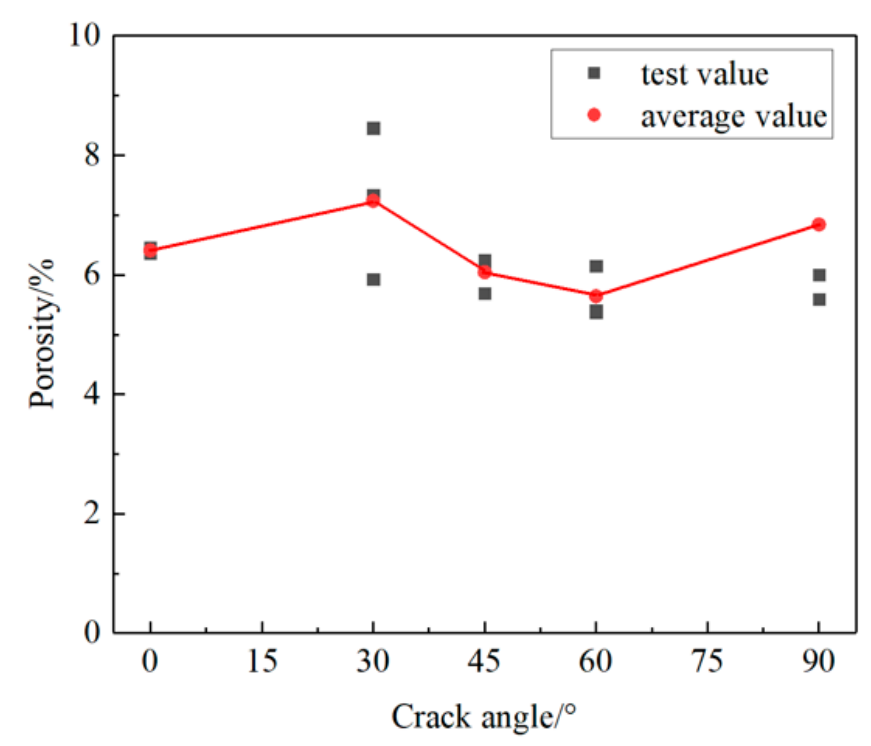

(b)

Figure 3. Porosity of specimens under different F-T cycles and crack angles: (a) $0^{\circ}$ angle crack, different F-T cycles; (b) different angle crack, 100 F-T cycles.

Figure 4 presents the evolution characteristics of $\mathrm{T}_{2}$ spectrum areas of different pore sizes. Figure 4 shows that the $T_{2}$ spectrum area of micropores ranges from 542.46 to 781.69 . The $T_{2}$ spectrum area of mesopores ranges from 1299.81 to 2621.83 . The $T_{2}$ spectrum area of macropores ranges from 175.37 to 1184.95 . In terms of the $T_{2}$ spectrum area, mesopores always account for the largest spectrum area among three types of pores. The $T_{2}$ spectrum area of micropores is larger than that of macropores when the number of F-T cycles is less than 80 . With the increase in F-T cycles, the $\mathrm{T}_{2}$ spectrum area of macropores surpasses that of micropores.

As displayed in Figure $4 a$, the average $T_{2}$ spectrum area of micropores fluctuates around 600 with the increase in F-T cycles. On the one hand, under the influence of F-T weathering, the generation of new pores and expansion of micropores increase the number and size of micropores, thus increasing the $\mathrm{T}_{2}$ spectrum area of micropores. On the other hand, some micropores develop and expand to mesopores; therefore, the $T_{2}$ spectrum area decreases at the same time. Under this dual action, the spectrum area of micropores shows a fluctuating trend.

The $T_{2}$ spectrum area of mesopores increases significantly and shows a linear growth trend with the increase in F-T cycles. The average $T_{2}$ spectrum area of mesopores increases from 1595.35 to 2357.03 , accounting for a total increase of 761.68 and a growth rate of $47.74 \%$. The steady increase in mesopore spectrum area mainly comes from the continuous development of micropores and mesopores.

As displayed in Figure $4 c$, the $T_{2}$ spectrum area of macropores gains the most significant growth with the increase in F-T cycles. The $\mathrm{T}_{2}$ spectrum area of macropores increases quadratically from 235.48 to 1032.60 , accounting for a growth of 797.12 and a growth rate of $338.51 \%$. This is because macropores are the ultimate form of other types of pores. The development and expansion of mesopores and macropores increase the $\mathrm{T}_{2}$ spectrum area of macropores. With the increase in F-T cycles, the pore structure is more likely to be developed due to the accumulation of damage, and the growth rate of the spectrum area also shows an increasing trend. 


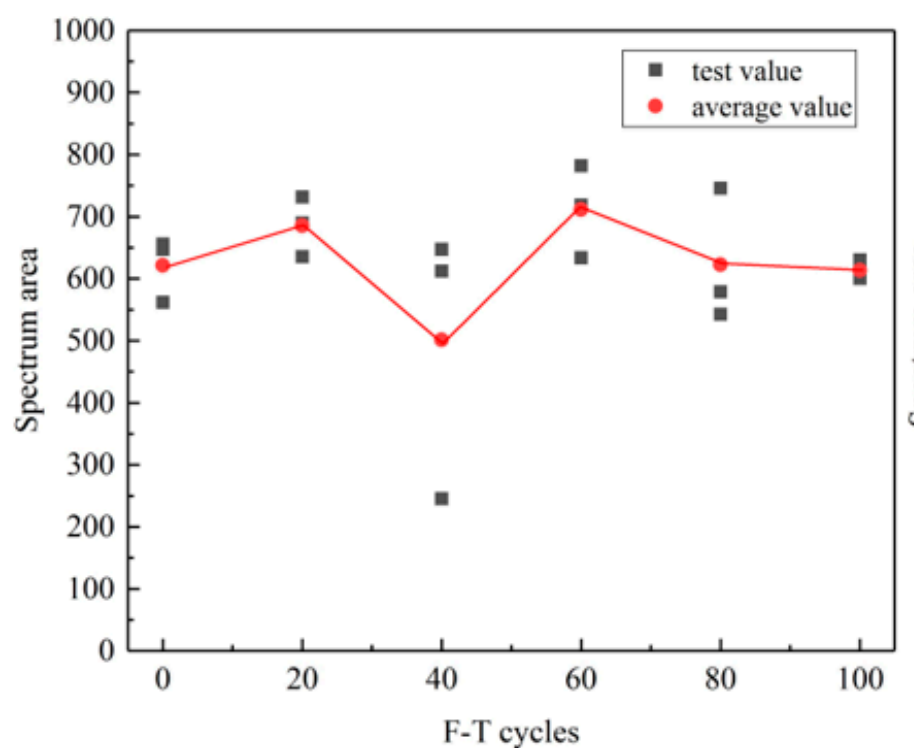

(a)

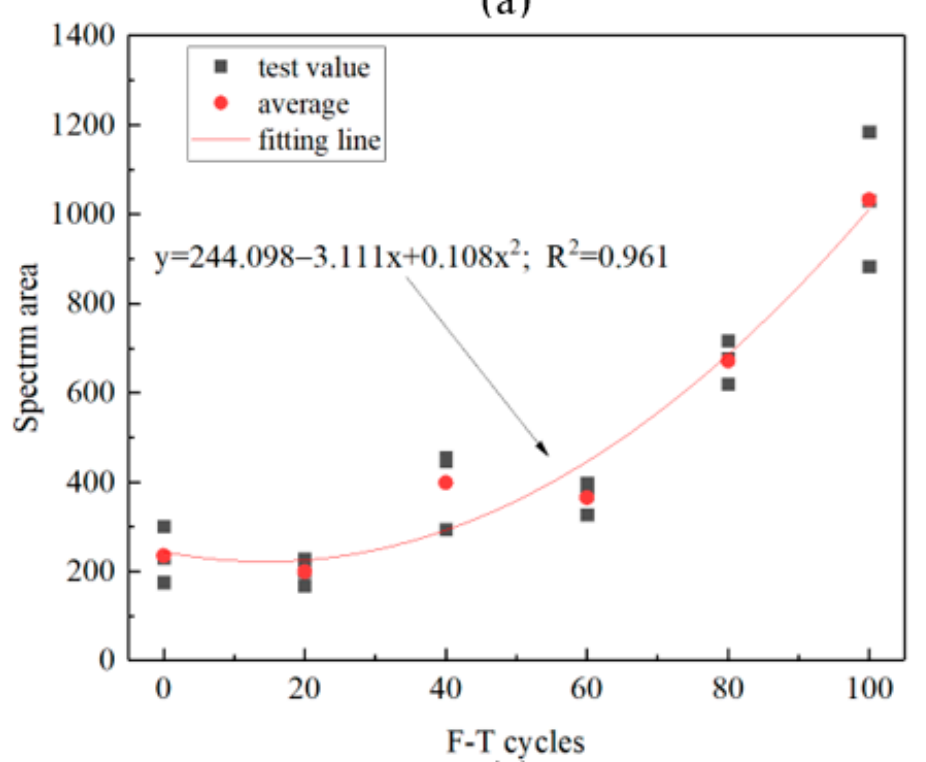

(c)

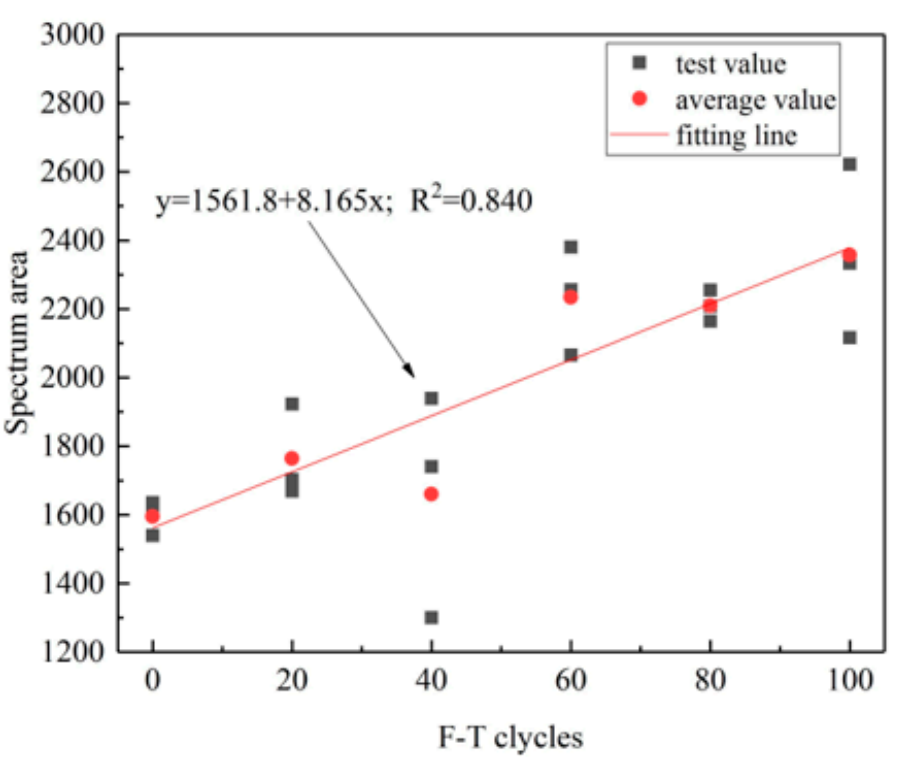

(b)

Figure 4. $\mathrm{T}_{2}$ spectrum area of different pore sizes versus F-T cycles: (a) micropore; (b) mesopore; (c) macropore.

\subsection{Compressive Mechanical Properties}

\subsubsection{Stress-Strain Curves}

It is evident that F-T cycles and crack angles exert different influences on stress-strain curves, as shown in Figure 5. With respect to the effect of the action of F-T cycles, F-T weathering brings variant changes at different stages. The compaction stage extends with the increase in the F-T cycles. In the linear elastic stage, the slope of the linear elastic stage decreases with the increase in F-T cycles. Peak stress also decreases in some way as the number of F-T cycles grows. For the post-peak of the stress-strain curve, as seen in Figure 5a, the drop mode transforms from rapid drop to a slower drop.

This is mainly attributed to the continuous initiation and development of pore structure in rock-like materials, which promotes an increase in porosity and structural degradation. With regards to the variation in post-peak curve, it indicates that rock-like materials gradually transform from brittle to ductile under cyclic freezing-thawing.

Figure $5 b$ displays a different variation trend of stress-strain curves under different crack angles. When the crack angle in rock-like material is $90^{\circ}$, the peak stress and slope of that curve are the maximum, while the peak strain is the minimum. The slope of that curve 
and the peak stress are the smallest when the crack angle is $45^{\circ}$, while the peak strain is the largest. The static characteristics of rock-like material show a certain law concerning variation in the crack angle.

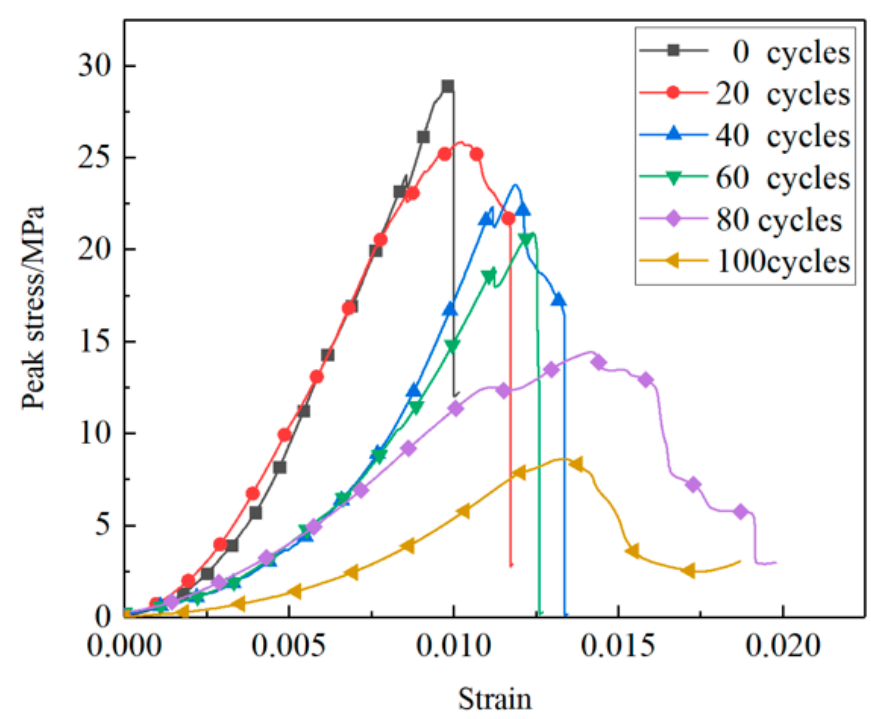

(a)

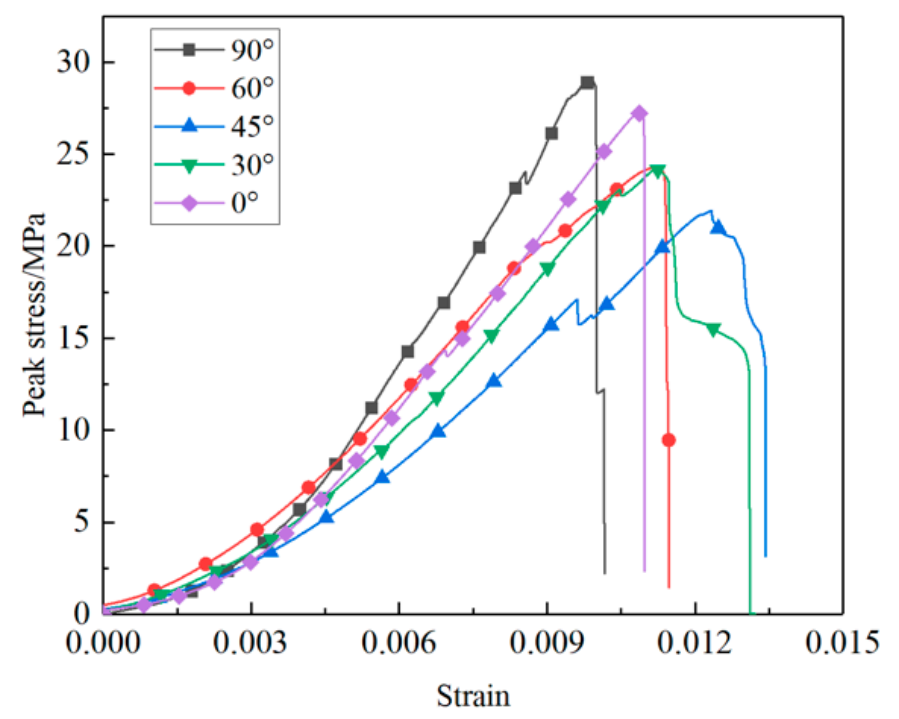

(b)

Figure 5. Stress-strain curves of specimens under various F-T cycles and angles crack: (a) $0^{\circ}$ angle crack, different F-T cycles; (b) 0 F-T cycle, different crack angles.

Particularly, a feature occurs in Figure 5 that attracts special attention; namely the stress-strain curves of rock-like material show irregular and obvious stress drop in the plastic yield stages. This is mainly caused by the sudden development of cracks in the stress concentration area near the prefabricated cracks, which is the result of temporary stress unloading under strong loads.

\subsubsection{Peak Stress}

Peak stress of specimens under different F-T cycles and crack angles are shown in Figure 6. Peak stress of specimens containing $0^{\circ}$ angle cracks that underwent various F-T cycles are presented in Figure 6a. Peak stress of specimens containing various crack angles that underwent 0 F-T cycles are presented in Figure $6 \mathrm{~b}$. Considering the length of this paper, peak stress of specimens that underwent other F-T cycles and crack angles are represented by Figure $6 \mathrm{a}, \mathrm{b}$, so they are not presented.

As shown in Figure 6a, the peak stress of specimens decreases linearly as F-T cycles increase. For instance, the average initial peak stress is $27.24 \mathrm{MPa}$, while its value drops to 23.75 MPa, 21.52 MPa, 17.74 MPa, 10.75 MPa, and 9.39 MPa after specimens suffered 20, 40, 60,80 , and $100 \mathrm{~F}-\mathrm{T}$ cycles, respectively, accounting for drop rates of $12.81 \%, 21.00 \%, 34.88 \%$, $60.58 \%$, and $65.53 \%$, correspondingly. This is mainly because F-T cycles accumulated damage in specimens by developing the pore structure of specimens. Additionally, the degree of cementation between mineral particles also decreased under F-T weathering.

As shown in Figure 6b, peak stress shows a V-type variation trend. Namely, peak stress decreases first, and then it increases with an increase in crack angle. The peak stress is the greatest when the crack angle is $90^{\circ}$, which is $28.16 \mathrm{MPa}$. The peak stress is the second greatest when the crack angle is $0^{\circ}$, which is $27.24 \mathrm{MPa}$. When the crack angle is $45^{\circ}$, peak stress reaches the minimum value, which is $21.35 \mathrm{MPa}$. 


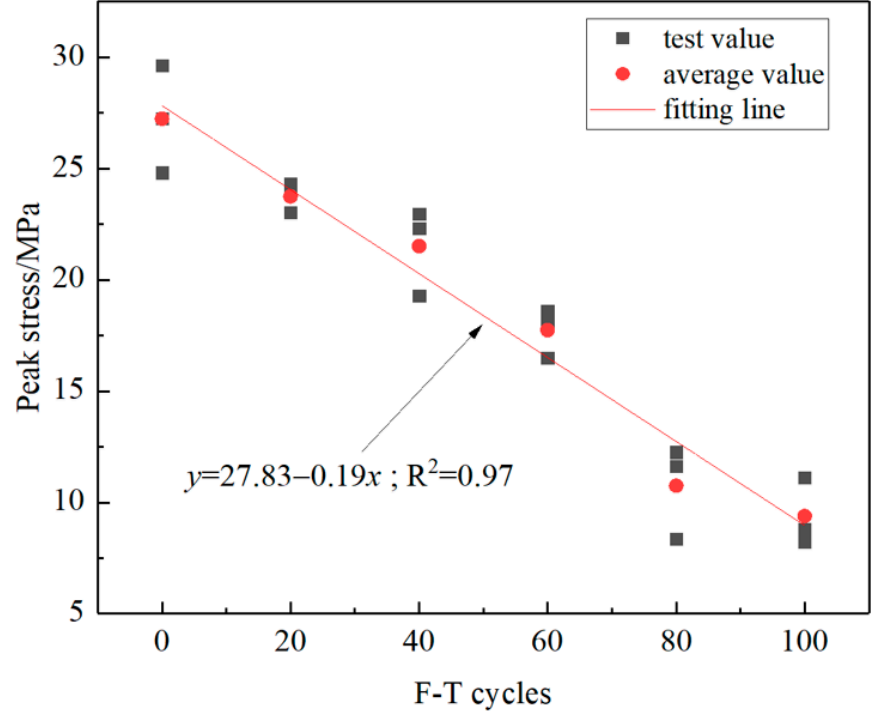

(a)

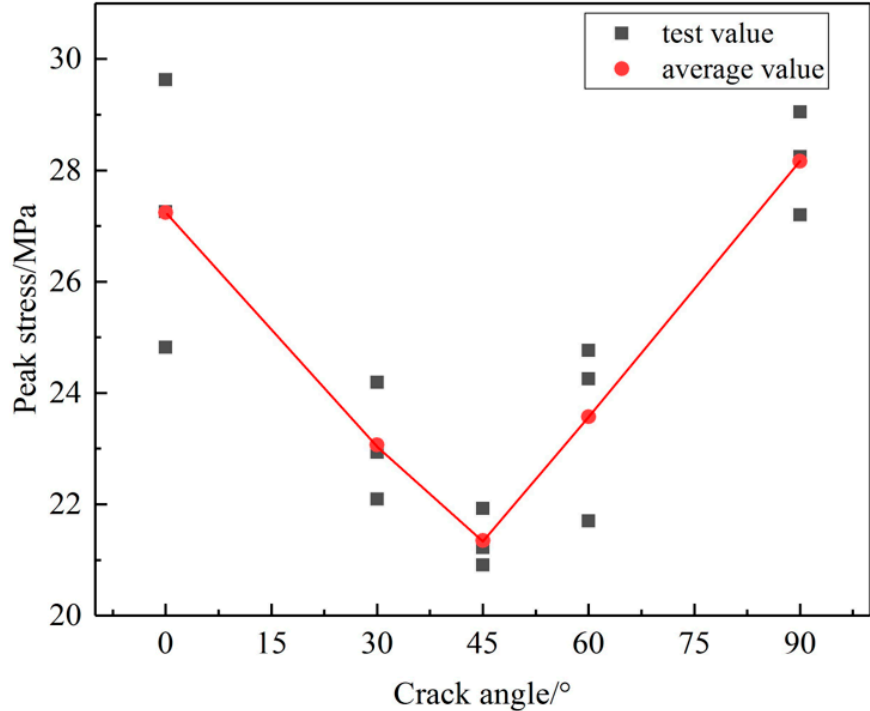

(b)

Figure 6. Peak stress evolution of specimens under various F-T cycles and crack angles: (a) $0^{\circ}$ angle crack, different F-T cycles; (b) 0 F-T cycles, different crack angles.

\subsubsection{Peak Strain}

As shown in Figure 7, peak strain presents a completely different variation trend compared to peak stress. Figure 7a displays that peak strain increases nonlinearly with the increase in F-T cycles, shifting from a slow rise to a rapid rise with the increase in F-T cycles. For instance, the average initial peak strain is 0.0110 , and its value reaches $0.0111,0.0112$, $0.0130,0.0152$, and 0.0174 , respectively, after 20, 40, 60, 80 and 100 F-T cycles, corresponding to growth rates of $0.91 \%, 1.82 \%, 18.18 \%, 38.18 \%$, and $58.18 \%$, respectively.

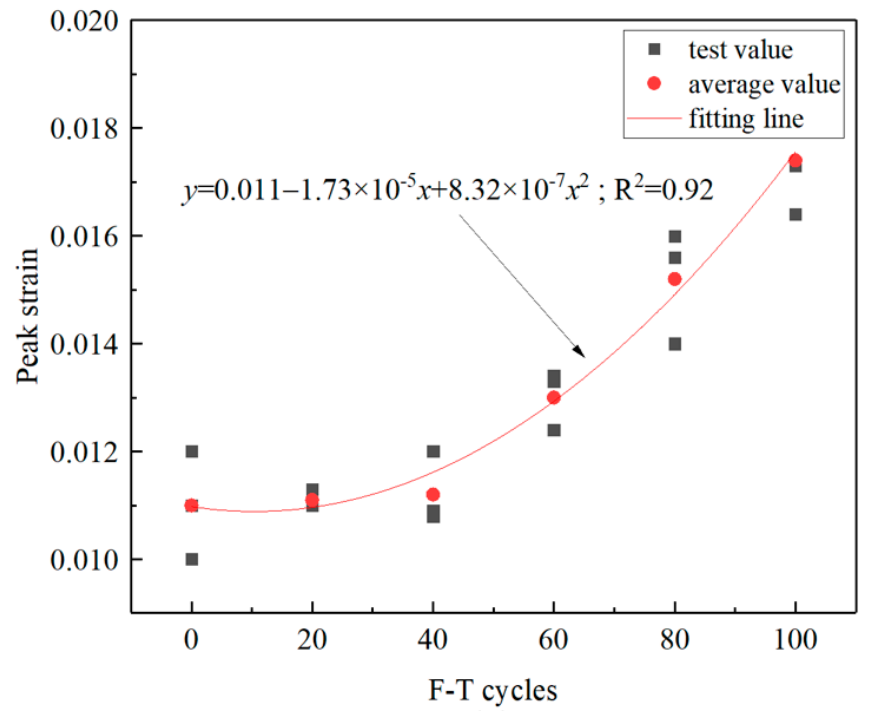

(a)

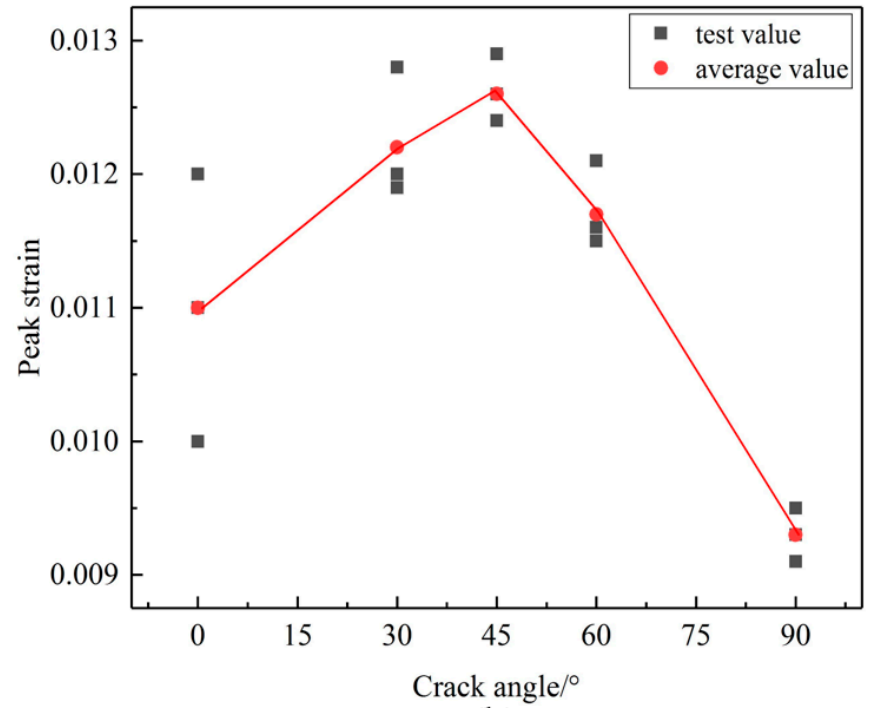

(b)

Figure 7. Peak strain evolution of specimens under F-T cycles and crack angles: (a) $0^{\circ}$ angle crack, different F-T cycles; (b) 0 F-T cycles, different crack angles.

As shown in Figure $7 \mathrm{~b}$, peak strain shows a reverse V-type variation trend. Namely, peak strain increases first and then decreases as crack angles increase. Peak strain is least when the crack angle is $90^{\circ}$, which is 0.0093 . Peak stress is the second least when the crack angle is $0^{\circ}$, which is 0.0110 . When the crack angle is $45^{\circ}$, peak stress reaches the 
maximum value, 0.0126 . It is easy to find that the variation trend of peak strain is opposite to peak stress.

\subsubsection{Elastic Modulus}

As seen in Figure 8a, elastic modulus shows a similar variation trend with peak stress: it decreases linearly as F-T cycles increase. More specifically, the average initial elastic modulus is $3.68 \mathrm{GPa}$, and it drops to $3.03 \mathrm{GPa}, 2.84 \mathrm{GPa}, 2.17 \mathrm{GPa}, 1.05 \mathrm{GPa}$, and $0.93 \mathrm{GPa}$, respectively, after 20,40,60, 80, and $100 \mathrm{~F}-\mathrm{T}$ cycles, corresponding to a drop rate of $17.66 \%, 22.83 \%, 41.03 \%, 71.47 \%$, and $74.73 \%$, respectively. This is caused by the gradual accumulation of freeze-thaw damage inside specimens.

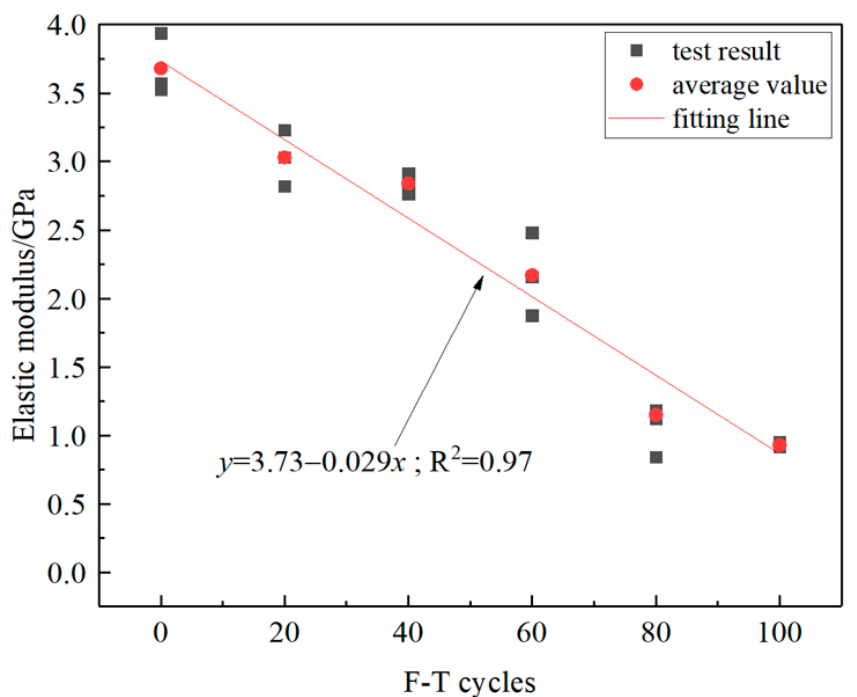

(a)

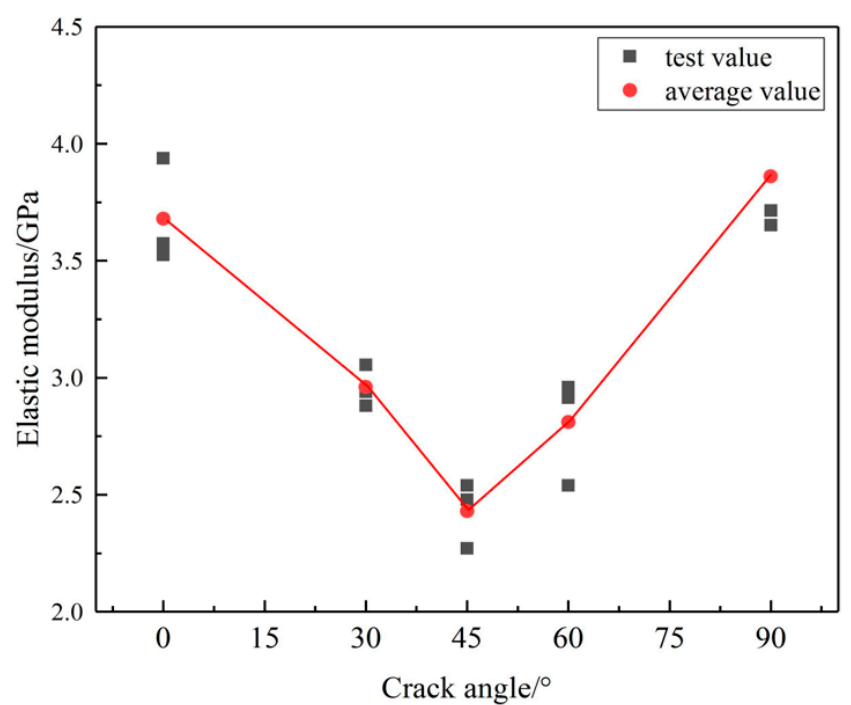

(b)

Figure 8. Elastic modulus evolution of specimens under various F-T cycles and crack angles: (a) $0^{\circ}$ angle crack, different F-T cycles; (b) 0 F-T cycle, different crack angles.

\subsection{Strain Energy}

Strain energies include dissipation energy, elastic strain energy, and pre-peak strain energy, calculated by integrating the stress-strain curve [40]. The variation trends of strain energies with F-T cycles and crack angles are analyzed in this section. Figure 8 displays the variation of strain energies with F-T cycles. As shown in Figure 9a, dissipation energy does not show an obvious trend with an increase in F-T cycles. Combined with the characteristics of the stress-strain curve of specimens, it is considered that this phenomenon is mainly caused by the difference in stress drop due to the development of prefabrication cracks in the pre-peak stage. The stress drop caused by the initial development of prefabricated cracks is random, and it has a direct impact on dissipated energy. Therefore, dissipation energy does not show an obvious trend with the increase in F-T cycles.

As shown in Figure 9b,c, the elastic strain energy and the pre-peak strain energy show an obvious variation law. Namely, they shift from a slow decrease to a rapid decrease with the increase in F-T cycles. More specifically, taking specimens containing a $0^{\circ}$ angle crack as an example, the average elastic strain energy drops from the initial $20.20 \mathrm{~J}$ to $19.87 \mathrm{~J}$, $16.19 \mathrm{~J}, 16.25 \mathrm{~J}, 11.07 \mathrm{~J}$, and $5.27 \mathrm{~J}$, respectively, after they suffered 20, 40, 60, 80, and $100 \mathrm{~F}-\mathrm{T}$ cycles. As for pre-peak strain energy, the average value drops from the initial $23.81 \mathrm{~J}$ to $27.19 \mathrm{~J}, 24.77 \mathrm{~J}, 23.01 \mathrm{~J}, 21.20 \mathrm{~J}$, and $8.78 \mathrm{~J}$ after they suffered 20, 40, 60, 80, and $100 \mathrm{~F}-\mathrm{T}$ cycles, respectively.

In Figure 10, variations in strain energies with crack angles are presented. As shown in Figure 9, it can be found that dissipation energy and pre-peak strain energy fluctuate as crack angles increase and show no obvious variation trend, while elastic strain energy 
shows an obvious evolution trend with the increase in crack angles. The detailed analysis on the influence of crack angles on strain energies is discussed later.

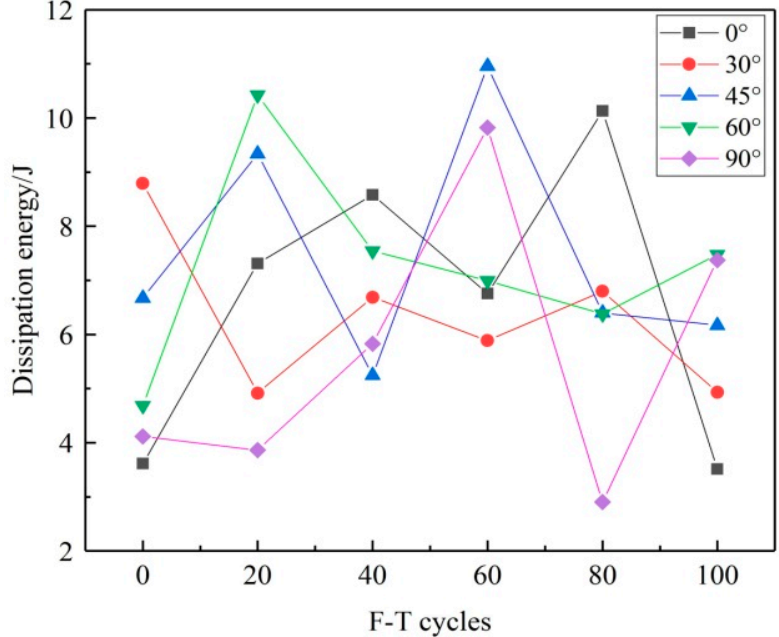

(a)

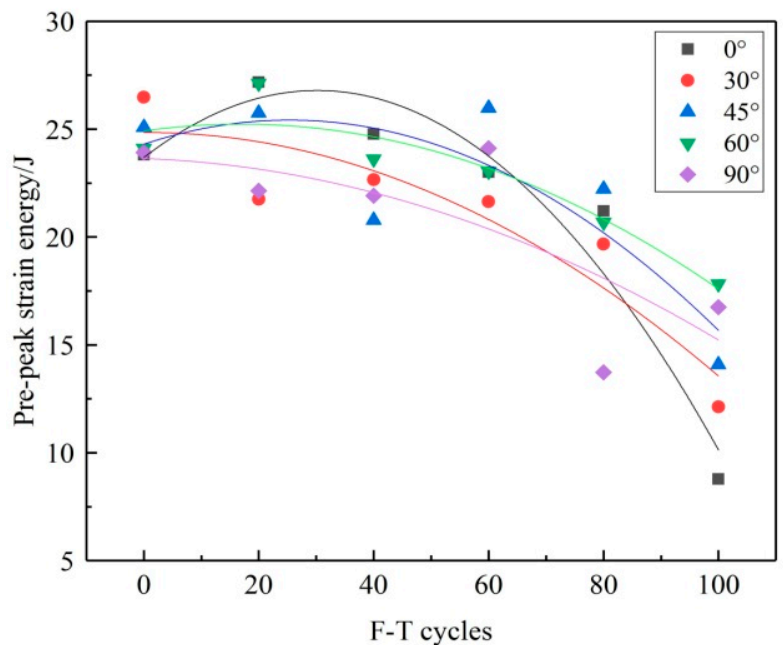

(c)

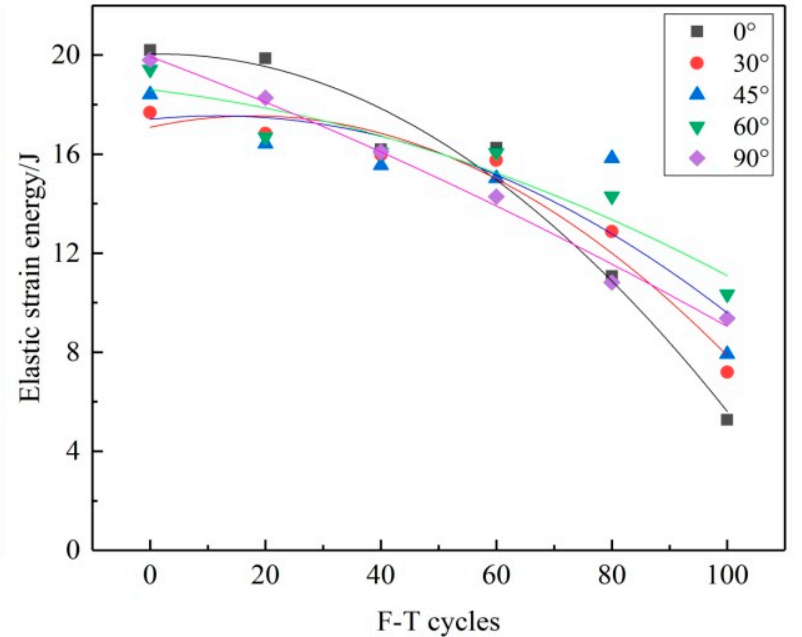

(b)

Figure 9. Strain energy evolution of specimens under different F-T cycles: (a) dissipation energy; (b) elastic energy; (c) pre-peak strain energy.

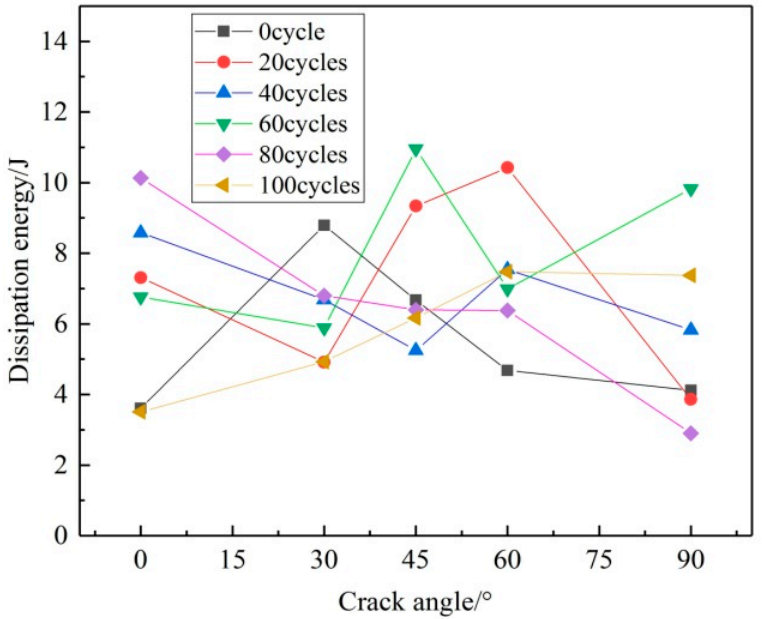

(a)

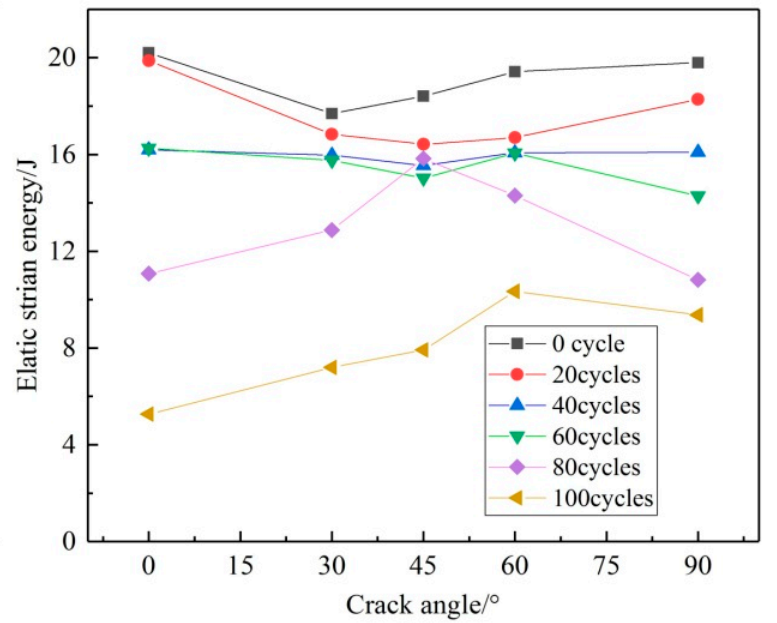

(b)

Figure 10. Cont. 


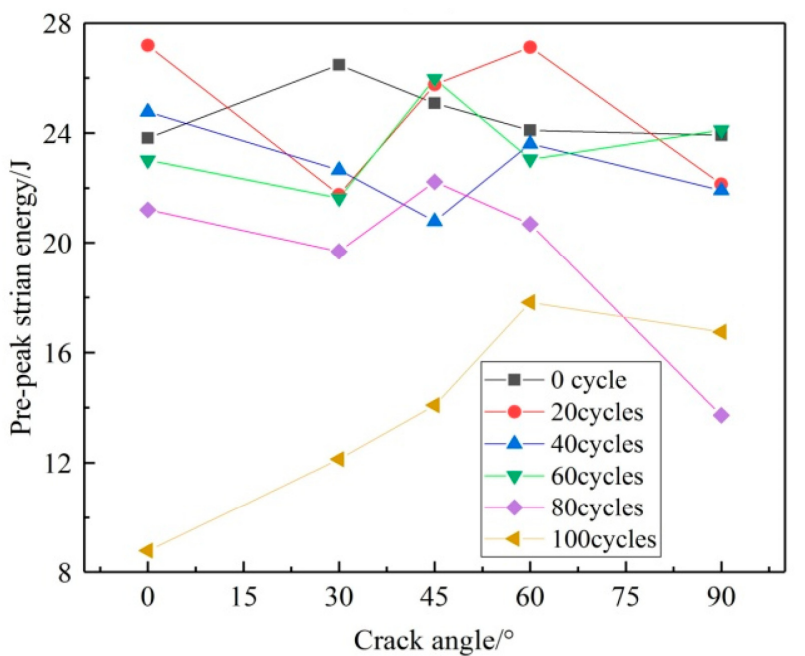

(c)

Figure 10. Strain energy evolution of specimens under various crack angles: (a) dissipation energy; (b) elastic energy; (c) pre-peak strain energy.

\subsection{Connection between Pore Structure and Mechanical Properties}

The correlation between mechanical properties and pores of different size range varies. Some pores may have effects on mechanical properties, while others may not. In this section, the relationship between pores with different sizes and mechanical properties is analyzed. Taking elastic modulus of specimens that underwent different numbers of F-T cycles as a representative example, the relationship between different types of pores and elastic modulus is analyzed.

As shown in Figure 11, the spectrum area of micropores shows no obvious change with elastic modulus, while relationships among the spectrum area of mesopores, the spectrum area of macropores, the spectrum area of full-size pores, and elastic modulus are obvious. Among these types of pores, the correlation between the spectrum area of macropores and elastic modulus is the highest, the correlation between the spectrum area of full-size pores and elastic modulus is the medial, and the correlation between the spectrum area of mesopores and elastic modulus is the smallest. Their correlation coefficients are 0.80 , 075 , and 0.64 , respectively. This indicates that the elastic modulus of the specimen is mostly affected by macropores. The influence of macropores on other mechanical parameters is also the greatest among all types of pores, but due to the limitation of paper length, they are not presented and analyzed one by one.

Except for the relationship between elastic modulus and macropores spectrum area shown in Figure 11c, the relationship between macropore spectrum area and other mechanical parameters is shown in Figure 12. As shown in Figures 11c and 12, peak stress, peak strain, and elastic modulus of the specimens under F-T cycles are well correlated with the spectrum area of macropores, though their variation trends are different.

As shown in Figures 11c and 12a, the peak stress and elastic modulus of specimens decrease exponentially with the increase in macropore spectrum area. When the spectrum area of macropores is less than 800 , the peak stress and elastic modulus decrease rapidly with the spectrum area of macropores. When the spectrum area of macropores is greater than 800 , the peak stress and elastic modulus decrease slowly.

According to the above analysis, it can be seen that because macropores are rapidly generated and expanded in the early stage of F-T cycles, which weakens the structure and internal cementation properties of specimens, the result is a rapid decline in elastic modulus and peak stress. When the spectrum area of macropores develops to the threshold value, the macropores inside begin to merge and form small cracks. Formation of these small cracks results in the more rapid growth of the macropore spectrum area than before. However, when specimens are under static uniaxial compression, small cracks are compacted and 
closed, which has little attenuation and weakening effect on the mechanical properties. Therefore, when the spectrum area of macropores exceeds 800 , the rate of decrease of peak stress and elastic modulus become obviously slower.

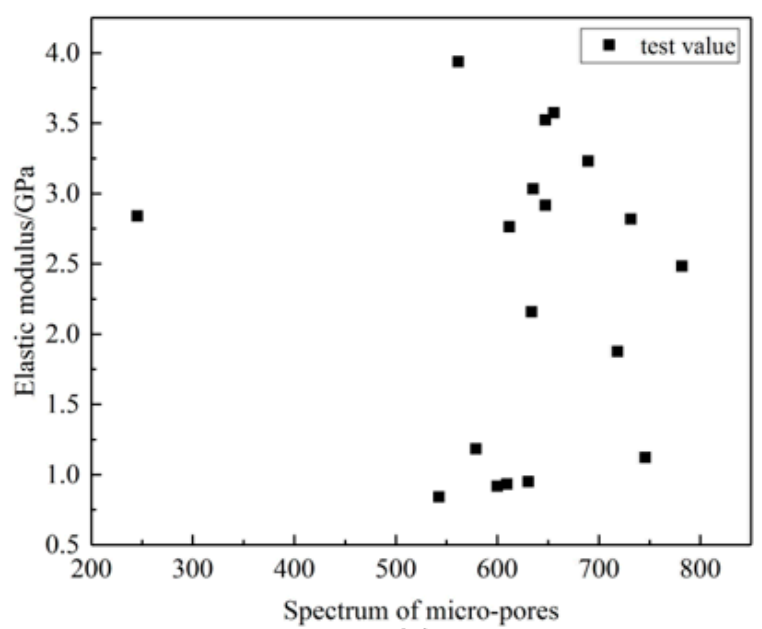

(a)

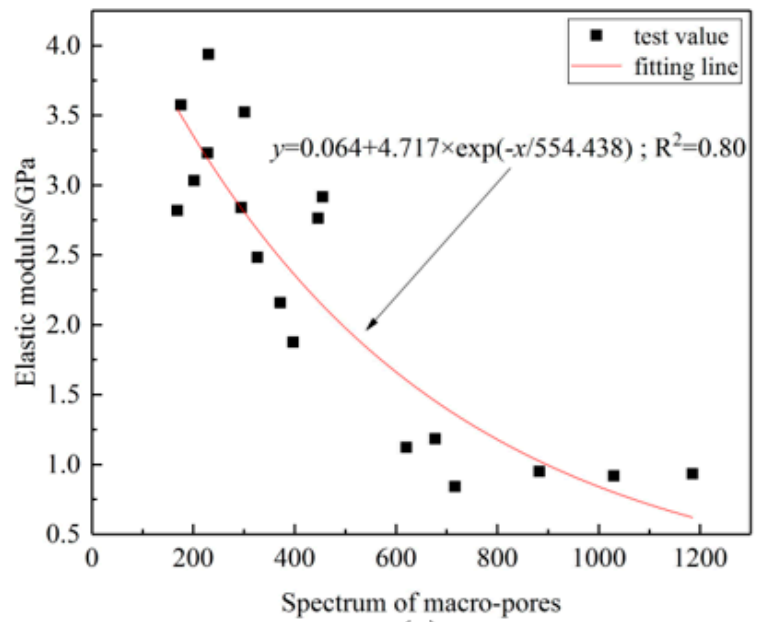

(c)

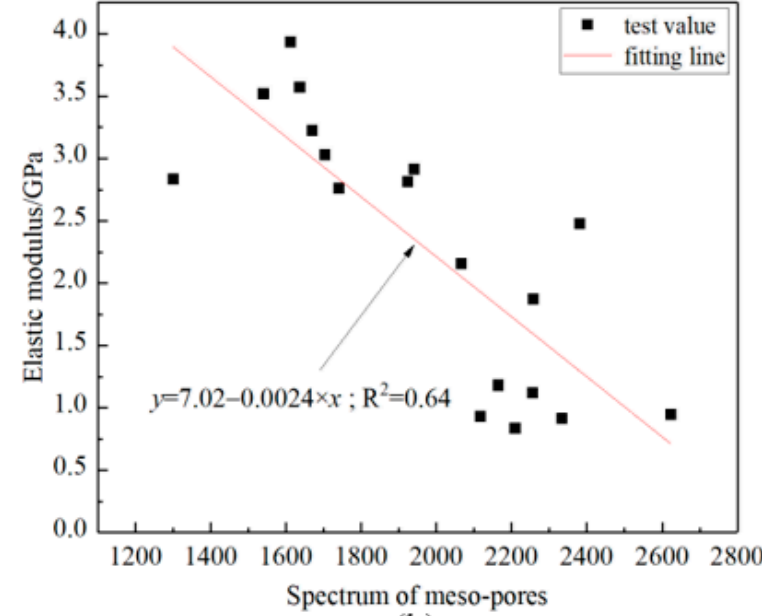

(b)

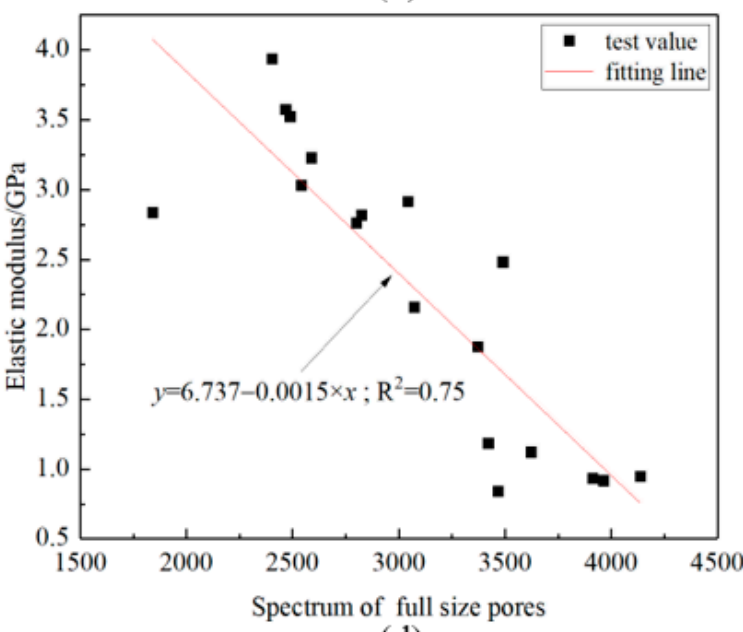

(d)

Figure 11. Relationship between elastic modulus and spectrum area of various pores: (a) micropore spectrum area; (b) mesopore spectrum area; (c) macropore spectrum area; (d) full-size pore spectrum area.

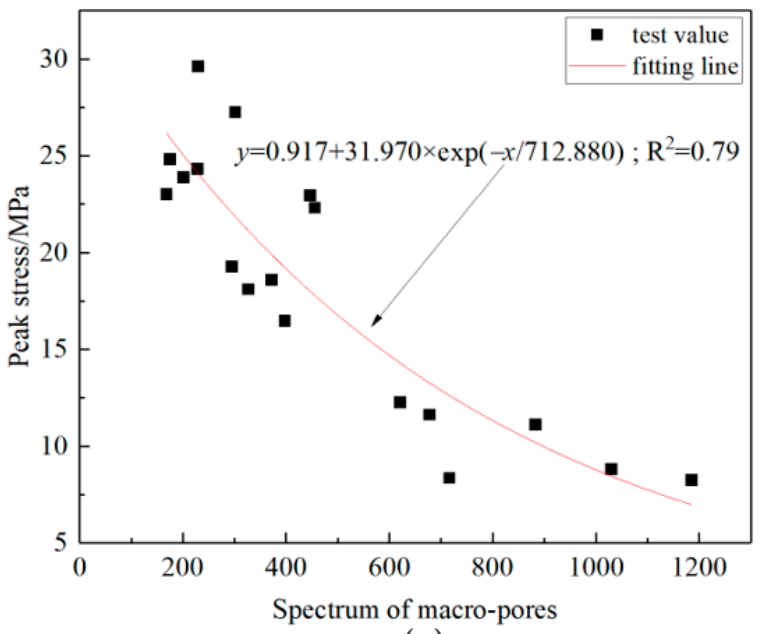

(a)

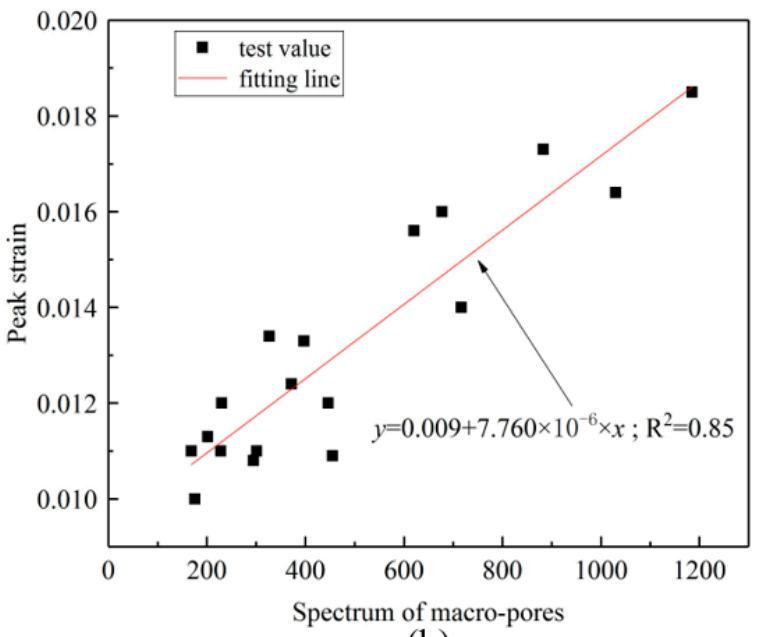

(b)

Figure 12. Relationship between elastic modulus and mechanical parameters: (a) peak stress; (b) peak strain. 
As shown in Figure 12b, peak strain increases linearly with the increase in in macropore spectrum area. This is mainly because macropores are compressible pores within specimens. With the increase in the macropore spectrum area, deformation of the specimen under compression also increases. In addition, with the increase in macropore spectrum area, damage to the specimen is aggravated, internal cementation of the specimen becomes weak and softened, and deformation of specimens becomes easier; therefore, peak strain also increases.

\section{Discussion}

\subsection{Variation of Mechanical Properties \\ 4.1.1. Peak Stress}

The linear decrease in peak stress mainly results because F-T cycles accumulate damage in specimens by developing the pore structure of specimens, while circumstances vary for those samples containing different crack angles.

Peak stress shows a V-type variation trend. It is believed that the existence of cracks changes the stress distribution inside specimens, leading variation of peak stress. When the crack angle is $0^{\circ}$ or $90^{\circ}$, the existence of the crack causes stress redistribution and stress concentration around the crack. When the axial stress reaches a higher level, tensile cracks form along the stress concentration area of the crack, and tensile failure is finally generated, but it does not facilitate the formation of shear cracks.

However, when the crack angle is $45^{\circ}$, the stress field around the prefabricated crack is close to the maximum effective shear stress when specimens are under uniaxial compression [51]. In other words, the existence of a $45^{\circ}$ crack triggers the failure of specimens in the shear mode. Therefore, a $45^{\circ}$ crack provides convenient conditions for specimen fracture, failure becomes easier, and peak stress drops dramatically. For those specimens containing $30^{\circ}$ and $60^{\circ}$ angle cracks, the stress distribution is somewhere between those two states; hence, their peak stresses are also between the greatest and least peak stresses.

\subsubsection{Peak Strain}

As shown in Figure 7a, the nonlinear variation trend of peak strain with F-T cycles is mainly caused by two factors. Firstly, micropores and mesopores increase rapidly in the early stage of F-T weathering, while compressible macropores increase slowly. Therefore, in the early stage of F-T weathering, the compressible space of specimens is relatively small, resulting in a short compaction stage. Secondly, the internal damage caused by cyclic freeze-thaw action softens the internal structure and deteriorates the mechanical bearing capacity of specimens. Damage and deterioration are processes of accumulation. Therefore, under the influence of the above two factors, peak strain of specimens under freeze-thaw weathering shows a nonlinear trend.

In terms of the reverse variation trend of peak strain, as analyzed in Section 3.2.2, when the crack angle is $0^{\circ}$ or $90^{\circ}$, the failure mode of specimens is tensile failure affected by stress concentration and stress distribution. The failure is mainly caused by transverse tensile action, and the longitudinal compression effect is relatively limited, so the peak strain of the specimen is low. When the crack angle is $45^{\circ}$, the specimen is also affected by longitudinal compression and transverse tension. However, in this case, failure is mainly dominated by shear, which reflects the dominant position of longitudinal compression. Under longitudinal compression, shear sliding occurs, and the peak strain at this stage is greater. When crack angles are $30^{\circ}$ and $60^{\circ}$, stress and failure mode are between these two states, and peak strains are also between the greatest and least values.

\subsubsection{Elastic Modulus}

The decrease in elastic modulus indicates the resistance ability of specimens to deform under external loading decreases. The elastic modulus linear decrease is mainly caused by two factors. First of all, frost heave force generated by the cyclic freeze-thaw weathering continuously squeezes the pore structure and promotes continuous pore generation and 
development. The development of pore structure results in a reduction in continuous structure, which can bear the external force. In addition, the repeated shrinking and expansion of mineral components and cementing materials inside the rock caused by temperature variation continuously deteriorates the cementing materials and mineral components; thus, the carrying structure of the cementing materials and mineral components is constantly softened. To sum up, with the increase in F-T cycles, the resistance of specimens to deformation under external load decreases continuously, and the elastic modulus of specimens also decreases continuously.

Similar to peak stress, elastic modulus shows a V-type variation trend with an increase in crack angle. The elastic modulus is the greatest when the crack angle is $90^{\circ}$, which is $3.86 \mathrm{GPa}$. The peak stress is the second greatest when the crack angle is $0^{\circ}$, which is $3.68 \mathrm{GPa}$. When the crack angle is $45^{\circ}$, peak stress reaches the minimum value, namely, $2.43 \mathrm{GPa}$. It is also believed that the existence of cracks changes the stress distribution inside the specimen, leading to the variation in elastic modulus, just as peak stress varies.

\subsection{Strain Energy}

In terms of elastic strain energy and pre-peak strain energy, they drop nonlinearly with the increase in F-T cycles. There are two main reasons for this. One is that cyclic F-T weathering causes accelerating growth of macropores, which leads to gradual deterioration of pore structure inside specimens. In addition, mineral composition and cementing material within specimens undergo frost heave and shrinkage due to the action of temperature variation. Consequently, mineral composition and cementing material are softened to certain degree, and carrying capacity and energy storage capacity of specimens are eventually reduced. Therefore, elastic strain energy and pre-peak strain energy nonlinearly decrease with F-T cycles.

In terms of irregular trends of energy dissipation and pre-peak strain energy, they are mainly caused by the difference in stress drop due to the development of prefabrication cracks in the pre-peak stage. In terms of the variation of elastic strain energy with crack angles, it first drops and then rises as the crack angle increases, as shown in Figure 10b. In Figure 10b, when the number of F-T cycles is less than 60 , the elastic strain energy reaches the maximum value when the crack angle is $0^{\circ}$ or $90^{\circ}$, while the elastic strain energy reaches the minimum value when then crack angle is $45^{\circ}$. When the crack angle is $45^{\circ}$, the crack is closest to the direction of the maximum effective shear stress. In this situation, mechanical parameters including peak stress and elastic modulus are at minimum values and specimens are most prone to shear failure; therefore, elastic strain energy stored by specimens is at a minimum.

When the number of F-T cycles surpass 60, the variation of elastic modulus changes. This may be caused by the continuous accumulation of macropores due to cyclic freezethaw weathering. This weakens the structural anisotropy caused by prefabricated cracks. Therefore, the random structure of specimens caused by freeze-thaw damage results in elastic strain energy breaking out of the previous variation trend.

\subsection{Failure Characteristics}

Specimens show different failure characteristics under different F-T cycles and crack angles. Figure 13 displays failure characteristics of specimens containing $45^{\circ}$ angle cracks under various F-T cycles. As shown in Figure 13, both tensile cracks (marked as 1 in Figure 13) and shear cracks (marked as 2 in Figure 13) occur on the surface of specimens. For specimens containing $45^{\circ}$ angle crack, their failure results from a combination of tensile failure and shear failure.

F-T cycles bring changes to the failure characteristics of specimens. In terms of the failure patterns of specimens, the number of cracks generated on the surface of specimens increases with the increases in F-T cycles, and secondary cracks are mainly distributed near the prefabricated crack and through cracks. As shown in Figure 13a, there are only two through shear cracks, a tensile crack, and a secondary shear crack on the surface of 
the specimen when the number of F-T cycles is 0 . When the number of F-T cycles is 80 , in addition to a shear crack and a tensile crack, there are two secondary tensile cracks and four secondary shear cracks. The phenomenon of increasing cracks with increased number of F-T cycles is mainly caused by the further development of pore structure and damage accumulation, which is caused by attenuation of cementation force. Under this condition, cracks are more easily formed under static compression.

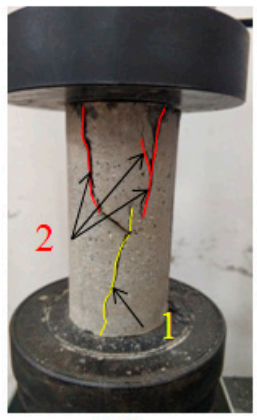

(a)

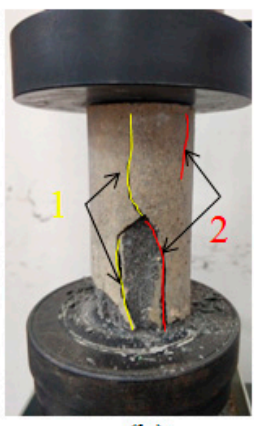

(b)

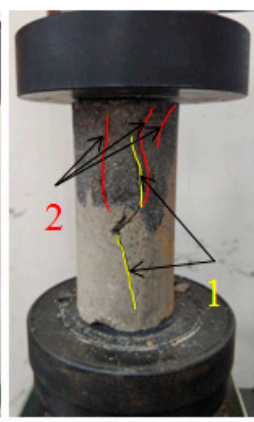

(c)

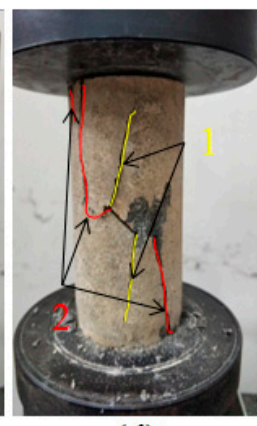

(d)

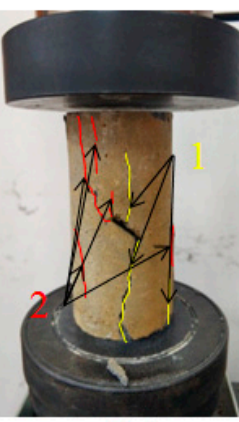

(e)

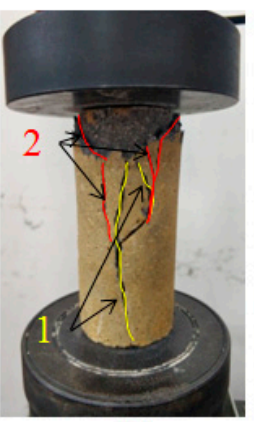

(f)

Figure 13. Failure modes of specimens containing $45^{\circ}$ crack under different F-T cycles: (a) 0 cycles; (b) 20 cycles; (c) 40 cycles; (d) 60 cycles; (e) 80 cycles; (f) 100 cycles.

Additionally, as shown in Figure 13b,c, the fragments ejected from specimens that underwent 20 and $40 \mathrm{~F}-\mathrm{T}$ cycles are larger, while the fragments ejected from the specimen that underwent 100 F-T cycles, shown in Figure 13f, are smaller. This indicates that specimens gradually transform from brittle to ductile as the number of F-T cycles increases.

Figure 14 presents the influence of crack angles on failure characteristics. As shown in Figure 14, failure modes of specimens obviously change with the change in crack angles. As shown in Figure 14a,e, when the angles of prefabricated cracks are $0^{\circ}$ and $90^{\circ}$, only tensile cracks occur on the surface of specimens. These cracks start from the stress concentration area, located at the end of the prefabricated crack, and extend to the loading end, and their directions are consistent with the loading direction.

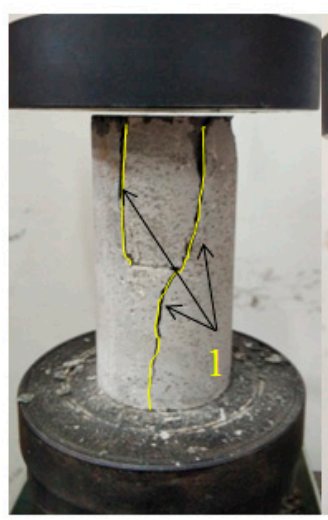

(a)

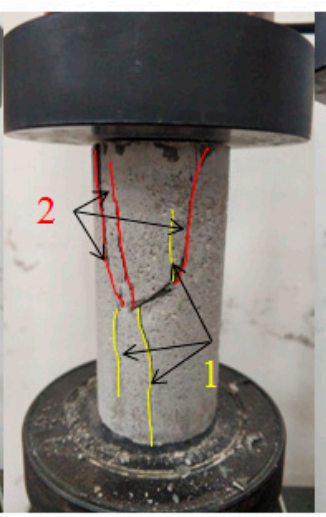

(b)

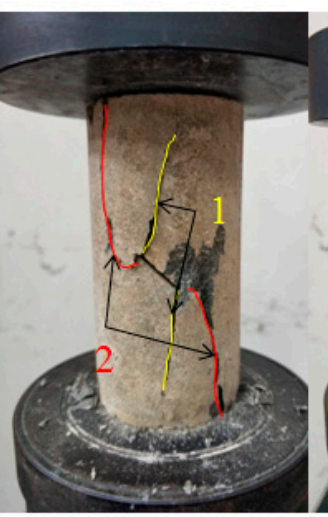

(c)

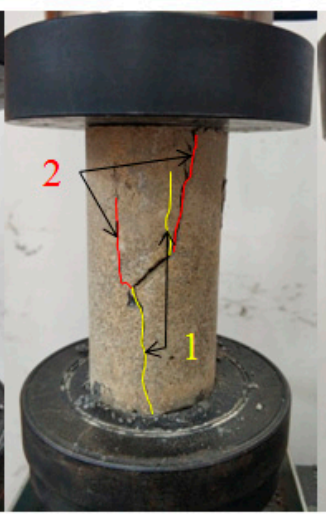

(d)

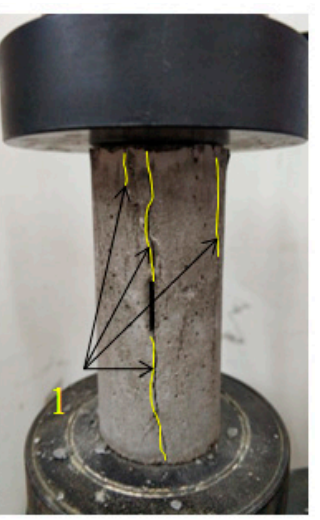

(e)

Figure 14. Failure modes of specimens containing various crack angles under 0 F-T cycles: (a) $0^{\circ}$ (b) $30^{\circ}$ (c) $45^{\circ}$ (d) $60^{\circ}$ (e) $90^{\circ}$.

When the crack angle is $45^{\circ}$, there are two types of cracks formed on the surface of the specimen: tension cracks and shear cracks. As shown in Figure 14c, the shear cracks deviate from the loading direction, while the tension crack is basically in the same direction as the loading direction. The shear cracks start from the stress concentration area, located at both ends of the prefabricated crack, and then penetrate to the loading end. The tension cracks also start from the stress concentration area at both ends of the prefabricated crack, but they do not penetrate to the loading end. This indicates that the dominant failure mode of the rock-like specimen is a shear failure when the crack angle is $45^{\circ}$. 
When the crack angles are $30^{\circ}$ and $60^{\circ}$, the failure characteristics of specimens are more complex. As shown in Figure $14 \mathrm{~b}, \mathrm{~d}$, specimens contain $30^{\circ}$ and $60^{\circ}$ cracks exhibit a mix of tensile and shear failure. This shows that the failure of the rock-like specimen is the result of a combination of shear failure and tensile failure.

\section{Conclusions}

By conducting freeze-thaw experiments and NMR tests on rock-like specimens containing cracks at various angles, mechanical properties, pore structure, strain energies, and failure characteristics of rock-like specimens were obtained and analyzed. Conclusions are drawn as follows:

(1) Porosity increases linearly with an increase in F-T cycles, while porosity shows no previous variation trend with change in crack angle. The spectrum area of mesopores shows a linear growth trend with an increase in F-T cycles, and the spectrum area of macropores increases quadratically with an increase in F-T cycles.

(2) Peak stress and elastic modulus drop linearly with an increase in F-T cycles, and peak strain increases nonlinearly with an increase in F-T cycles. Peak stress and elastic modulus decrease in the beginning, and then they increase with an increase in crack angle, while peak strain first increases and then decreases with an increase in crack angle.

(3) Fissipation energy fluctuates with an increase in F-T cycles, and elastic strain energy and pre-peak strain energy drop nonlinearly with F-T cycles. Dissipation energy and pre-peak strain energy fluctuate with an increase in crack angle, and elastic strain energy first decreases and then increases with and increase crack in angle when the number of F-T cycles is less than 60 .

(4) The correlation between spectrum area of macropores and elastic modulus is the most significant among the different types of pores. Elastic modulus and peak stress decrease exponentially with an increase in macropore spectrum area, and peak strain increases linearly with an increase in macropore spectrum area.

Finally, it is worth noting that the conclusions obtained above are based on rock-like specimens. These conclusions are of an orienting nature, and it will be necessary to compare the results from this paper with tests on real rock material in the future.

Author Contributions: Conceptualization, S.Y. and H.D.; methodology, S.Y. and Y.K.; software, J.D.; validation, G.T., J.D. and H.D.; formal analysis, S.Y., Y.K. and H.D.; investigation, S.Y. and G.T.; resources, H.D.; data curation, S.Y.; writing-original draft preparation, S.Y. and G.T.; writingreview and editing, Y.K., S.Y., H.D. and J.D.; visualization, S.Y. and G.T.; supervision, H.D.; project administration, H.D.; funding acquisition, H.D. and Y.K. All authors have read and agreed to the published version of the manuscript.

Funding: This research was jointly supported by the National Natural Science Foundation of China (NSFC) (Grant No. 51804135, 51874352) and the Natural Science Foundation of Jiangxi Province (Grant No.20192BAB216017).

Data Availability Statement: The data used to support the findings of this study are available from the corresponding author upon request.

Conflicts of Interest: The authors declare no conflict of interest.

\section{References}

1. Park, J.; Hyun, C.U.; Park, H.D. Changes in microstructure and physical properties of rocks caused by artificial freeze-thaw action. Bull. Eng. Geol. Environ. 2015, 74, 555-565. [CrossRef]

2. Ke, B.; Zhang, J.; Deng, H.; Yang, X. Dynamic Characteristics of Sandstone under Coupled Static-Dynamic Loads after Freeze-Thaw Cycles. Appl. Sci. 2020, 10, 3351. [CrossRef]

3. Song, Z.; Wang, Y.; Konietzky, H.; Cai, X. Mechanical behavior of marble exposed to freeze-thaw-fatigue loading. Int. J. Rock Mech. Min. Sci. 2021, 138, 104648. [CrossRef]

4. Mu, J.; Pei, X.; Huang, R.; Rengers, N.; Zou, X. Degradation characteristics of shear strength of joints in three rock types due to cyclic freezing and thawing. Cold Reg. Sci. Technol. 2017, 138, 91-97. [CrossRef] 
5. Liu, T.; Zhang, C.; Li, J.; Zhou, K.; Cao, P. Detecting freeze-thaw damage degradation of sandstone with initial damage using NMR technology. Bull. Eng. Geol. Environ. 2021, 80, 4529-4545. [CrossRef]

6. Cai, X.; Cheng, Q.; Zhou, Z.; Konietzky, H. Rock mass watering for rock-burst prevention: Some thoughts on the mechanisms deduced from laboratory results. Bull. Eng. Geol. Environ. 2021, 80, 8725-8743. [CrossRef]

7. Meng, F.; Zhai, Y.; Li, Y.; Zhao, R.; Li, Y.; Gao, H. Research on the effect of pore characteristics on the compressive properties of sandstone after freezing and thawing. Eng. Geol. 2021, 286, 106088. [CrossRef]

8. Wang, D.; Chen, G.; Jian, D.; Zhu, J.; Lin, Z. Shear creep behavior of red sandstone after freeze-thaw cycles considering different temperature ranges. Bull. Eng. Geol. Environ. 2021, 80, 2349-2366. [CrossRef]

9. Zhang, Q.; Li, Y.; Chen, Q. Effects of temperatures and $\mathrm{pH}$ values on rheological properties of cemented paste backfill. J. Cent. South Univ. 2021, 28, 1707-1723. [CrossRef]

10. Xu, J.; Pu, H.; Sha, Z. Mechanical behavior and decay model of the sandstone in Urumqi under coupling of freeze-thaw and dynamic loading. Bull. Eng. Geol. Environ. 2021, 80, 2963-2978. [CrossRef]

11. Qiao, C.; Li, C.; Wang, Y.; Yang, H.; Song, Z. Research on macro and meso damage model of pre-flawed granites subjected to coupling action of freeze-thaw and loading. Arab J. Geosci. 2021, 14, 1083. [CrossRef]

12. Song, Z.; Frühwirt, H.; Konietzky, H. Inhomogeneous mechanical behaviour of concrete subjected to monotonic and cyclic loading. Int. J. Fatigue 2019, 132, 105383. [CrossRef]

13. Weng, L.; Wu, Z.; Taheri, A.; Liu, Q. Deterioration of dynamic mechanical properties of granite due to freeze-thaw weathering: Considering the effects of moisture conditions. Cold Reg. Sci. Technol. 2020, 176, 103092. [CrossRef]

14. Weng, L.; Wu, Z.; Liu, Q.; Chu, Z.; Zhang, S. Evolutions of the unfrozen water content of saturated sandstones during freezing process and the freeze-induced damage characteristics. Int. J. Rock Mech. Min. Sci. 2021, 142, 104757. [CrossRef]

15. $\mathrm{Lu}, \mathrm{Y}$; $\mathrm{Li}, \mathrm{X}$.; $\mathrm{Wu}, \mathrm{X}$. Fracture coalescence mechanism of single flaw rock specimen due to freeze-thaw under triaxial compression. Rock Soil Mech. 2014, 35, 1579-1584.

16. Liu, H.; Liu, Y.; Xing, C.; Zhang, L.; Ma, M. Test study of damage failure of jointed rock mass under freezing-thawing cycles. Rock Soil Mech. 2014, 35, 1547-1554.

17. Si, K.; Cui, Z.; Peng, R.; Zhao, L.; Zhao, Y. Crack Propagation Process and Seismogenic Mechanisms of Rock Due to the Influence of Freezing and Thawing. Appl. Sci. 2021, 11, 9601. [CrossRef]

18. Jia, H. Theoretical Damage Model of Porous Rock and Hard Joint Rocks Subjected to Forest Action and Further Experimental Verification. Ph.D. Thesis, China University of Geoscience, Wuhan, China, 2016.

19. Zhai, J.; Zhang, Z.; Melnikov, A.; Zhang, M.; Yang, L.; Jin, D. Experimental Study on the Effect of Freeze-Thaw Cycles on theMineral Particle Fragmentation and Aggregation with Different Soil Types. Minerals 2021, 11, 913. [CrossRef]

20. Xu, P.; Wu, Y.; Huang, L.; Zhang, K. Study on the Progressive Deterioration of Tunnel Lining Structures in Cold Regions Experiencing Freeze-Thaw Cycles. Appl. Sci. 2021, 11, 5903. [CrossRef]

21. Jia, H.; Zi, F.; Yang, G.; Li, G.; Shen, Y. Influence of Pore Water (Ice) Content on the Strength and Deformability of Frozen Argillaceous Siltstone. Rock Mech. Rock Eng. 2020, 53, 967-974. [CrossRef]

22. Roy, D.; Singh, T.; Kodikara, J. Effect of water saturation on the fracture and mechanical properties of sedimentary rocks. Rock Mech. Rock Eng. 2017, 50, 2585-2600.

23. Chen, Q.; Sun, S.; Liu, Y.; Qi, C.; Zhou, H. Immobilization and leaching characteristics of fluoride from phosphogypsum-based cemented paste backfill. Int. J. Miner. Metall. Mater. 2021, 28, 1440-1452. [CrossRef]

24. Mousavi, S.; Tavakoli, H.; Moarefvand, P.; Rezaei, M. Micro-structural, petro-graphical and mechanical studies of schist rocks under the freezing-thawing cycles. Cold Reg. Sci. Technol. 2020, 174, 103039. [CrossRef]

25. Javier, M.; Benavente, D.; Gomez-Heras, M. Marco-Castañoa, L.; García-del-Curaac, Á. Non-linear decay of building stones during freeze-thaw weathering processes. Constr. Build. Mater. 2013, 38, 443-454.

26. Ruiz, V.G.; Rey, R.; Celorio, C.; Suárezdel, L.M.; Calleja, L. Characterization by Computed X-ray tomography of the evolution of the pore structure of a dolomite rock during freeze-thaw cyclic tests. Phys. Chem. Earth Part A Solid Earth Geod. 1999, 24, 633-637.

27. Raynaud, D.; Mazerolle, F. Analysis of the internal structure of rocks and characterization of mechanical deformation by a non-destructive method: X-ray tomodensitometry. Teetonophysics 1989, 159, 149-159. [CrossRef]

28. Kucharczyková, B.; Šimonová, H.; Kocáb, D.; Topolář, L. Advanced Evaluation of the Freeze-Thaw Damage of Concrete Based on the Fracture Tests. Materials 2021, 14, 6378. [CrossRef]

29. Li, J.; Zhou, K.; Liu, W.; Deng, H. NMR research on deterioration characteristics of microscopic structure of sandstones in freeze-thaw cycles. Transac. Nonferrous Metals Soc. China 2016, 26, 2997-3003. [CrossRef]

30. Gao, F.; Wang, Q.; Deng, H.; Zhang, J.; Tian, W.; Ke, B. Coupled effects of chemical environments and freeze-thaw cycles on damage characteristics of red sandstonE. Bull. Eng. Geol. Environ. 2016, 76, 1481-1490. [CrossRef]

31. Deng, H.; Dong, C.; Li, J.; Zhou, K.; Tian, W.; Zhang, J. Experimental Study on Sandstone Freezing-Thawing Damage Properties under Condition of Water Chemistry. Appl. Mech. Mater. 2014, 608-609, 726-731. [CrossRef]

32. Deng, H.; Yu, S.; Deng, J. Damage Characteristics of Sandstone Subjected to Coupled Effect of Freezing-Thawing Cycles and Acid Environment. Adv. Civil Eng. 2018, 1-10. [CrossRef]

33. Liu, C.; Deng, H.; Chen, X.; Xiao, D.; Li, B. Impact of Rock Samples Size on the Microstructural Changes Induced by Freeze-Thaw Cycles. Rock Mech. Rock Eng. 2020, 1, 1-8. [CrossRef] 
34. Li, J.; Liu, H.; Ai, K.; Zhu, L. An NMR-Based Experimental Study on the Pore Structure of the Hydration Process of Mine Filling Slurry. Adv. Civil Eng. 2018, 1-12. [CrossRef]

35. Jia, H.; Ding, S.; Zi, F.; Dong, Y.; Shen, Y. Evolution in sandstone pore structures with freeze-thaw cycling and interpretation of damage mechanisms in saturated porous rocks. Catena 2020, 195, 104915. [CrossRef]

36. Qin, L.; Zhai, C.; Liu, S.; Xu, J.; Yu, G.; Sun, Y. Changes in the petrophysical properties of coal subjected to liquid nitrogen freeze-thaw-A nuclear magnetic resonance investigation. Fuel 2017, 194, 102-114. [CrossRef]

37. Song, Z.; Frühwirt, T.; Konietzky, H. Characteristics of dissipated energy of concrete subjected to cyclic loading. Constr. Build. Mater. 2018, 168, 47-60. [CrossRef]

38. Weng, L.; Huang, L.; Taheri, A.; Li, X. Rockburst characteristics and numerical simulation based on a strain energy density index: A case study of a roadway in Linglong gold mine, China. Tunnell. Undergr. Space Technol. 2017, 69, 223-232. [CrossRef]

39. Ma, Q.; Ma, D.; Yao, Z. Influence of freeze-thaw cycles on dynamic compressive strength and energy distribution of soft rock specimen. Cold Reg. Sci. Technol. 2018, 153, 10-17. [CrossRef]

40. Deng, H.; Yu, S.; Deng, J.; Ke, B.; Bin, F. Experimental Investigation on Energy Mechanism of Freezing-Thawing Treated Sandstone under Uniaxial Static Compression. KSCE J. Civil Eng. 2019, 23, 2074-2082. [CrossRef]

41. Zhang, J.; Deng, H.; Taheri, A.; Ke, B.; Liu, C. Deterioration and strain energy development of sandstones under quasi-static and dynamic loading after freeze-thaw cycles. Cold Reg. Sci. Technol. 2019, 160, 252-264. [CrossRef]

42. Liu, C.; Zhang, J.; Deng, H.; Lin, Y.; Li, P.; Ke, B. Energy Dissipation Characteristics and Failure Patterns of Freeze-Thawed Granite in Dynamic Flexural Tension. IEEE Access 2019, 7, 97793-97802. [CrossRef]

43. Cai, X.; Zhou, Z.; Zang, H. Water saturation effects on dynamic behavior and microstructure damage of sandstone: Phenomena and mechanisms. Eng. Geol. 2020, 276, 105760. [CrossRef]

44. Ke, B.; Zhou, K.; Xu, C.; Deng, H.; Li, J.; Bin, F. Dynamic Mechanical Property Deterioration Model of Sandstone Caused by Freeze-Thaw Weathering. Rock Mech. Rock Eng. 2018, 51, 2791-2804. [CrossRef]

45. Yu, S.; Deng, H.; Tian, G.; Deng, J. Microscopic Characteristic Analysis on Sandstone under Coupling Effect of Freeze-Thaw and Acidic Treatment: From Nuclear Magnetic Resonance Perspective. Appl. Sci. 2020, 10, 5699. [CrossRef]

46. Deng, H.; Tian, G.; Yu, S.; Zhang, J.; Zhong, Z.; Zhang, Y. Research on Strength Prediction Model of Sand-Like Material Based on Nuclear Magnetic Resonance and Fractal Theory. Appl. Sci. 2020, 10, 6601. [CrossRef]

47. Jian, K.; Zhao, M.; Zhao, Y. Random Non-homogeneous thermal elastic mechanics model and numerical tests on thermal cracking threshold of rock. Chin. J. Rock Mech. Eng. 2004, 23, 2331-2335.

48. Zhang, J.; Deng, H.; Liu, T.; Tian, G.; Tang, L. Study on Microstructural Evolution of Marble Under Cyclic Dynamic Impact Based on NMR. IEEE Access 2019, 7, 138043-138055.

49. Zhang, J.; Deng, J.; Deng, H.; Gao, R. Fractal Analysis of Pore Structure Development of Sandstone: A Nuclear Magnetic Resonance Investigation. IEEE Access 2019, 7, 47282-47293. [CrossRef]

50. Yan, J.; Wen, D.; Li, Z.; Geng, B.; Cai, J.; Liang, Q.; Yan, Y. The quantitative evaluation method of low permeable sandstone pore structure based on nuclear magnetic resonance (NMR) logging. Chin. J. Geophys. 2016, 59, 1543-1552.

51. Liang, Z.; Rao, J.; Huang, P.; Chen, J.; Liu, D.; Xie, C. Experimental Study on the Effect of Fracture Inclination on the Strength of Argillaceous Dolomite. Sci. Technol. Eng. 2019, 19, 305-312. 